\title{
Judging Standards
}

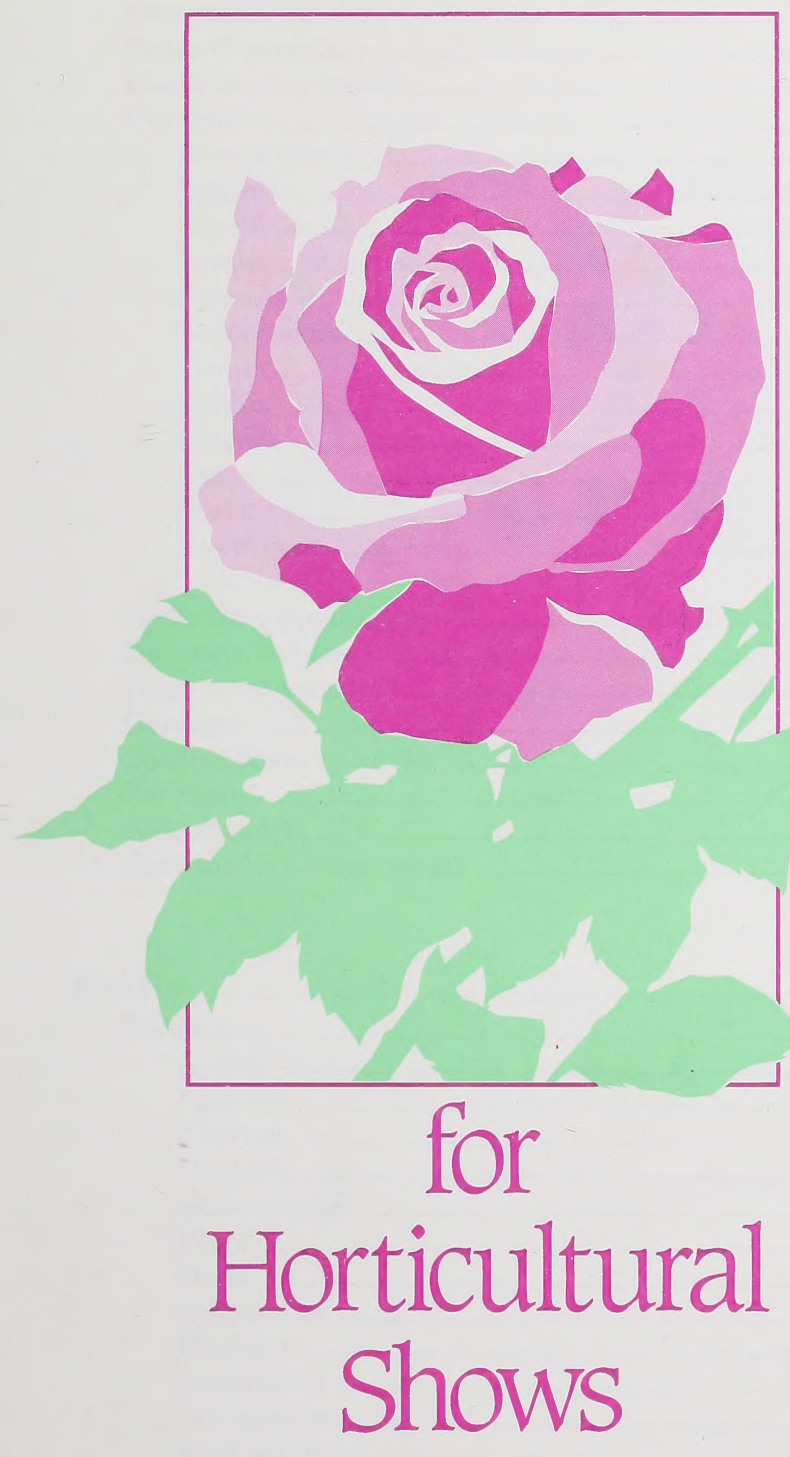


Copies of this publication may be obtained from:

Print Media Branch

Alberta Agriculture

$7000-113$ street

Edmonton, Alberta, T6H 5T6

OR

Alberta Agriculture's district offices

RV 198707 5M 
Systems of Judging

Planning a Show

Hints for show committees

Hints for exhibitors

Hints for judges

\section{Flowers}

Information for show committees

Notes to exhibitors

Clarification of terms

Cut flowers

Annual asters

Begonias

Marigolds

Pansies and violas

Petunias

Snapdragons

Zinnias

Dahlias

Gladiolus

Lilies

Roses

Sweet peas

Collections and displays __ 21

Bouquets and vases _ 21

Floral arrangements 21

Corsages 22

Shadow boxes or niches 22

Pot plants 22

African violets 24

Cacti and other succulents _- 24

Fruits 25

Definitions 26

Apples 27

Apricots 227

Cherries _ 27

Currants _ 27

Gooseberries — 27

Pears 228

Plums 28

Raspberries _ 28

Rhubarb — 28

Saskatoons _ 28

Strawberries 28

Fruit not listed 38

Preserves — 29

Fruit collections — 29

Fruit displays 29 
Collections

Standards of perfection 32

Beans $\quad 32$

Broad beans _ 33

Beets 33

Brussels sprouts _ 34

Cabbage —34

Carrots 35

Swiss Chard 37

Sweet corn 37

Cucumbers _ 38

Eggplant 39

Garden herbs _ 39

Kale 39

Kohlrabi —_. 39

Leeks _. 40

Lettuce — 40

Muskmelon 40

Onions — 40

Parsnips — 41

Peas _ 42

Peppers 42

Potatoes 43

Pumpkins 43

Radishes _ 42

Rhubarb — 44

Squash — 45

Tomatoes 46

Turnips - Rutabaga — 46

Watermelon 47

Other classes _ 47

\section{Yards and Gardens}

Information for show committees

Judging standards _ 47

Classes — 48

Agricultural Exhibits

Sheaf grain 49

Baled hay 50

Silage classes 51

Forage sheaves _ 51

Field crop seeds

Weed collections 
This recent revision of Judging Standards for Horticultural Shows will serve as a useful manual for interpreting the standards for garden competitions and horticultural exhibitions held in the prairie provinces. Although we hope it is a useful guide for both the judge and exhibitor, it should be understood that it is not the absolute authority. This recent revision reflects new ideas, trends and suggestions expressed by the authors as well as the users of this manual, and has been organized in a comprehensive and informative way for quick accurate reference.

\section{LYNN DENNIS}

Chairman, Horticulture Extension and Education Subcommittee Alberta Horticultural Advisory Committee 
Digitized by the Internet Archive in 2015

https://archive.org/details/judgingstandards00albe 


\section{Danish}

A modified Danish system of judging is generally used at competitions throughout the province, with the exception of fairs. However, some fairs are now adopting the Danish system.

Colored ribbons are used to indicate the placings. All items are judged against a standard and are given a rating. Therefore, several first placings, second placings, etc. may be awarded in each class.

First place articles are awarded 10,9 or 8 points. Second place articles receive 7, 6 or 5 points and thirds rate $4,3,2$ or 1 point.

\section{Fairs}

At most fairs (including flower shows and horticultural exhibitions) prizes are awarded to only the three best entries in each class. If no article in the class is of suitable standard, a prize will not be given. Therefore, in some classes, there may be no first, no second or possibly no third prize.

\section{Colors indicate merit}

Prize

1 st

2nd

3rd
Color

Red

Blue

White
Danish

4-3-2-1

\section{PLANNING A SHOW}

H.T. Allen, P.Ag. ${ }^{1}$

"So make thy garden fair as thou canst,

Thou workest not alone

Perchance he whose plot is next to thine

Will see it and mend his own.

- Elizabeth Rundle Charles

On the show bench, gardeners and would-be gardeners may observe a variety of excellent flowers, fruits and vegetables that can be grown in a particular region. It is this educational aspect that is the prime purpose for staging an exhibition of horticultural produce.

The annual show is the climax of the gardening year and affords growers an opportunity to display the fruits of their labor and compare the results of their endeavors with those of other gardening enthusiasts. For many, the honor of placing well in a competition is reward enough, and, for others, the prizes of merchandise or cash are of first importance. These awards, however, are often small compensation for the time and effort expended in displaying produce.

Exhibition committees, while giving full consideration to exhibitors, must keep in mind that the educational value of a horticultural show is its main justification for public support. The show itself, like a floral arrangement, should be staged for effect.

${ }^{1}$ Lacombe, Alberta (Retired) 


\section{Schedule}

The schedule is the most important preparation to be made for a horticultural show. The rules laid down must be clear and meaningful, to maintain a standard for fair competition.

- A committee should have the authority to rule on disputes arising from any misinterpretation of the schedule. Furthermore this committee must rule on whether or not exhibits have been home grown (as opposed to commercially grown in greenhouses, etc.) if doubt arises in the mind of the judge(s).

- The schedule makers must be clear in their own minds as to what is intended, and must word each class in such a way that there can be no doubt. For example, in a flower class, "six spikes each of three varieties" is definite, whereas "six spikes of at least three varieties" is definite only as to the minimum requirement. Similarly the term "any color" is vague and the schedule should indicate number of colors allowed i.e., one color, any two colors, etc.

- Conflicting terminology, such as "and”, “or”, "should”, "must”, should be avoided, since the wrong use of these words may convey an interpretation not intended. In a class described "red and white potatoes", for example, both types must be included in each exhibit.

- The number of specimens in a class may depend upon the popularity or ease of culture of a particular crop in the area. There is no reason, however, why many class requirements cannot be the same for many or all shows. Such uniformity would benefit exhibitors and judges as well as the schedule makers.

- Sizes, numbers and other details must be specified in the schedule.

- Through lack of quality or other factors, an exhibit may not deserve a first prize although it may be first in its class. The committee should rule, before judging commences, as to whether undeserving awards should be made. The rule adopted will vary from show to show but depends largely upon the size and newness of the show.

- If the committee rules that exhibits must be the property of the exhibitor then it must follow that only one person can exhibit from a particular garden. Perhaps all members of a household should be allowed to exhibit from one garden, providing one member exhibits in different classes from another. In many instances, the rules prohibit an exhibitor from entering more than one exhibit in one class. It is often better to allow more than one entry in a class from one person, providing the entries are distinctly different cultivars (varieties).

\section{Staging}

Staging refers to setting up and covering tables or benches, allocating space for the various classes, displaying the exhibits, and all the other numerous details of preparation before judging.

Most horticultural shows are one-day affairs, where the exhibits are staged, judged and disposed of all in a matter of a few hours. Considerable difficulty is experienced by show committees in not knowing until the final minute the numbers of exhibits to be staged in each class. This often leads to crowding and eventual last minute shifting, which is disconcerting to exhibitors. Nevertheless, each exhibit deserves equal opportunity for scrutiny by the judge. The following hints may be helpful:

- It is better to have an excess of bench space than not enough.

- A survey of the season may tell the committee which classes will likely have the most exhibits.

- Experience, and maintaining good year-to-year records, will tell the committee which classes are preferred.

- An easily moved table can be very useful to relieve crowded classes during judging.

- Exhibits may be shifted by the committee after judging to fill in empty spaces.

- The appearance of the show is greatly improved if tables or benches are covered. Black or white 3 to 5 mil polyethylene is one of the best covers as it is not stained by water and can be stored for reuse in subsequent years. It will last for many years if handled with reasonable care. 
- Colored ribbons or paper strips to separate the various classes are helpful to the judge as well as to the public.

- Classes should be arranged along the tables in the same order as they appear in the schedule. This arrangement avoids confusion and greatly speeds up judging.

- Good lighting is important to facilitate judging, as well as to enhance the appearance of the show.

- Class cards with letters large enough to be seen from a reasonable distance give an efficient businesslike appearance.

\section{Judges}

Judges are human beings, requiring body sustenance, reward for time expended and time to make a decision. They may not know all there is to know about the kinds and varieties of plants but they will always do their best to make a fair decision. Their decision should be final.

- Avoid asking judges to be present too long before you are ready for them. Their time is important.

- Keep unauthorized people out of the room while judging is being done. This rule should be rigidly enforced.

- Avoid rushing the judge. Endeavor to have entries staged early enough to allow ample time for judging before public showing.

- Arrange for clerks who do not have exhibits in the classes being recorded.

- Try to have labels of a standard type, for it is too easy to spot individualism if different kinds are used. Although labeling is important for educational purposes and should be encouraged, it should not influence the judge in making the placings (unless the schedule specifies that labels are to be considered).

- Do not expect the judge to rule on misinterpretations of the schedule. This is a committee responsibility.

- The judge should give written comments to the exhibitors on memo cards or "post-it notes" during the judging. This is very helpful, especially to new exhibitors.

\section{Hints for exhibitors}

First and foremost, if you are an exhibitor, be a good sport.

- Be on time with your exhibits. The criticism of the public for a show not opening on time is often aimed at the judges when, in fact, it is the fault of late exhibitors.

- Follow the schedule explicitly. If the rules or schedule are not clear, obtain a ruling before the show, not after. (Read the schedule carefully).

- Do not blame the show committee if they fail to bring to your attention that you have entered the wrong number of specimens in a class. It is your responsibility, not theirs.

- Label your entries with the correct cultivar (variety) name even though the schedule may not ask for it. This adds to the educational value of the show.

\section{Hints for judges}

\section{Philosophy}

Not every good grower, not every successful exhibitor, is temperamentally a reliable judge at the show table. The judicial temperament bespeaks fairness, impartiality, utter lack of prejudice, a thoroughly objective approach to the problem at hand and a firmness without obstinacy. In fairness to every exhibitor the judge must definitely examine each entry in the assigned class. The problem should be approached systematically, unhurriedly, yet proceed to a logical decision as rapidly as is consistent with careful, comprehensive examination and proper evaluation. In making an evaluation the judge should 
take into account the local growing and recent weather conditions.

A judge must be rule-conscious at all times and sensitive to classification errors or misplaced entries.

Judges, even experienced knowledgeable ones, do not always agree on the severity of a particular fault. There is no reason why they should. The difference in opinion reflects accurately the human element of judging.

Veteran judges must continue to apply their experience and ever increasing information to improve their professional ability as a judge. Learning never ceases.

\section{Responsibilities}

- Accept judging assignments graciously.

- Study the show schedule in advance of judging a show and adhere strictly to the rules of the show.

- Be on time.

- Be courteous and considerate to fellow judges, clerks and exhibitors.

- Be completely objective in your approach.

- Be prepared to point out the cogent reasons for your decisions in a diplomatic and confident manner.

- A judge, including any member of his or her family, must not have entries in any of the classes to be judged by that individual.

\section{FLOWERS Information for show committees}

E.W. Toop, P. Ag. ${ }^{2}$

In flower shows, the staging of exhibits contributes toward good judging and an attractive display. Ways and means should be considered to improve staging at all times.

To foster the interest of the public and exhibitors, flower arrangements should be placed so that individual exhibits have uniform lighting and ample room for display.

Show committees should consider purchasing suitable containers for the cultural classes to provide a measure of uniformity. If uniform containers are not provided, then the show committee might consider wrapping all containers.

The use of foliage in cut flower classes should be given consideration, as it may lead to nonuniformity. "Own" foliage has a clear meaning, whereas "other" foliage may allow such items as baby's breath, which is a flower. The schedule should specify.

\section{Notes to exhibitors}

Exhibitors are sometimes at a loss as to what constitutes an exhibit in some cultural classes:

- Individual blooms of flowers such as marigold and calendula are shown with only one open bloom per stem. If an extra bud is present, is must be in the "tight bud" condition so that it will not show color on the show bench.

- With flowers that have multiple blooms, such as sweet peas, stocks or phlox, the more blooms that are open the better the exhibit.

- In some cultural classes, for example, petunia, tuberous begonia, pansy and viola, the flower alone is judged; stem and foliage are not considered. Shallow containers allowing individual placement of the flowers should be used.

${ }^{2}$ Professor of Horticulture, Department of Plant Science, University of Alberta, Edmonton, Alberta. 


\section{Clarification of terms}

Although score cards may be quite clear to experienced exhibitors, they may mean very little to a novice. Terms found in the score cards are therefore included among the definitions (see Glossary).

\section{Cut flowers}

\section{Preparation for exhibit}

- Flowers should be cut in the late afternoon when food reserves are at their highest.

- Hardening flowers after cutting is important. Remove the lower foliage and place the cut flowers in lukewarm water $\left(43^{\circ} \mathrm{C}\right)$ for 12 to 24 hours before exhibiting. They can be placed in the light or dark but should not be stored with fruit. Air temperature should be between 5 and $10^{\circ} \mathrm{C}$. Many flowers, such as roses, increase in size by a quarter to a third during hardening.

- The bottom $1.5 \mathrm{~cm}(0.5 \mathrm{in}$.) of all stems should be cut off after hardening.

- Whether the cut on the end of the stem is square or slanted makes no difference, but it is easier to cut on a slant. Always make a fresh cut before putting a flower in water.

- Use of certain chemicals (flower preservatives) in the water prolongs the life of flowers on display. They also help keep red flowers from becoming bluish and tend to prevent shattering. Aspirin and Vitamin $B_{1}$ are of no value as preservatives in prolonging cut flower life.

- Length of stem does not seem to make any difference in keeping quality.

- Plants with milky or sticky sap usually benefit from searing the stem end in a flame or in $1.5 \mathrm{~cm}$ ( $0.5 \mathrm{in}$.) of boiling water for several minutes.

- Before hardening, woody-stemmed plants should have the stems split up from the bottom as much as 12 to $15 \mathrm{~cm}$ ( 5 to $6 \mathrm{in}$.), or have the lower 8 to $10 \mathrm{~cm}$ ( 3 to $4 \mathrm{in}$.) crushed with a hammer. This also applies to chrysanthemums, lilies, stocks and hollyhocks.

- After hardening, flowers may be kept 5 to 7 days in air-tight, moisture-proof cellophane packages, which can be sealed with a hot iron. Spray flowers with water before wrapping and store packages at 5 to $10^{\circ} \mathrm{C}$. Cut off $1.5 \mathrm{~cm}(0.5 \mathrm{in}$.) of the stem of each cut flower after removing from the package, and place in water.

- Depth of water in display containers makes no difference. Three $\mathrm{cm}(2 \mathrm{in}$.) of water is sufficient, except for carnations. The only value of deeper water is in reviving wilted flowers. Cold water, or even ice water, may help retain freshness on the show bench. Use thoroughly clean containers.

- To prolong the life of the flowers, change the water daily, recut the stem ends, and keep the flowers in a cool room at night. If preservative is used in the water then no changing of the water or recutting of stems is necessary.

\section{Judging standards}

The qualities to be considered, and the approximate importance each should be given in judging most cut-flower classes, are given below:

Condition

Form

Stem and foliage
30 Uniformity 10; substance (turgidity) 10; freedom from bruise and blemish 10 .

20 Uniformity 5; proper maturity (not over- or undermature) 5; proper shape (not misshapen) 5 ; proper petalage 5 .

20 Uniformity 5; strength and/or straightness 5; foliage quality 5 ; size and proportion 5. 
Color

Size

Total
20

10

100
Uniformity 5 ; intensity 5 ; clarity 5 ; brilliance 5 .

Uniformity 5 ; proper size for variety 5 .

\section{Criteria for establishing classes}

In establishing classes for some of the common cut flowers the criteria used are not always well defined. For example, classifying marigolds (Tagetes) as French or African is no longer desirable since many cultivars of these species are not typical of either. For setting up classes of marigolds and some of the other controversial cut flowers a few suggestions are given.

\section{ANNUAL ASTERS (CALLISTEPHUS)}

Base classes on flower diameter.

(1) under $8 \mathrm{~cm}$ (3 in.) diameter.

(2) $8 \mathrm{~cm}$ (3 in.) and over in diameter.

Further breakdown into classes based on flower color or other characteristics is possible.

\section{BEGONIAS (TUBEROUS ROOTED TYPE)}

There are many kinds of begonias but the large flowered tuberous begonias are the most popular for exhibition. They are actually perennial plants but handled as bedding plants outdoors. If they are included in a bench show it is best to make it clear whether they are to be considered a perennial cut flower or an "annual" or bedding plant cut flower. This will clarify to judge and exhibitor alike whether the class is placed in the proper category. I have seen begonias disqualified by a judge because they were put into an open class under "any other annual". The judge considered them a perennial flower.

Tuberous begonia flowers are best exhibited as individual blooms displayed in a shallow container (same as pansies and petunias), class may be set up for the different flower forms illustrated.

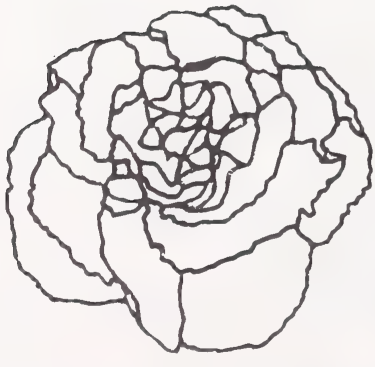

carnation flowered

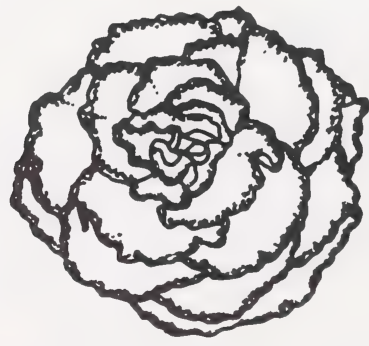

picotee type

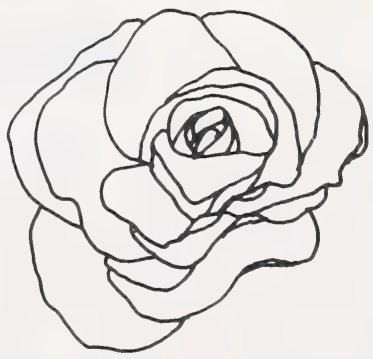

camelia flowered 


\section{MARIGOLDS (TAGETES)}

Base classes on flower diameter.

(1) under $4 \mathrm{~cm}$ (1.5 in.) diameter.

(2) 4 to $8 \mathrm{~cm}$ ( 1.5 to 3 in.) diameter.

(3) over $8 \mathrm{~cm}$ (3 in.) diameter.

May also be classified as singles, semidoubles and doubles.

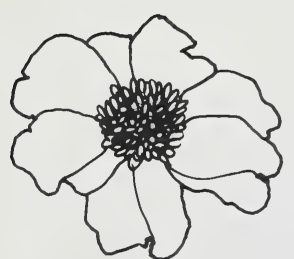

single

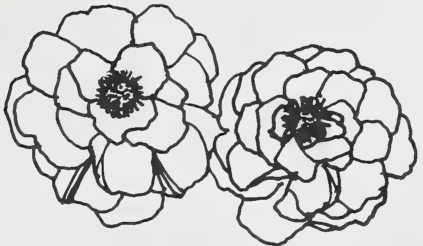

semi-double

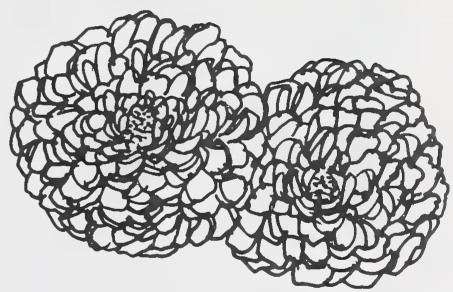

double

\section{PANSIES AND VIOLAS (VIOLA)}

The distinction between these flowers is not always clear. Rather than have separate classes for pansies and violas, classes based on flower diameters can be used to avoid misunderstandings, that is, under $2.5 \mathrm{~cm}$ ( 1 in.) diameter, $2.5 \mathrm{~cm}$ ( 1 in.) to $5 \mathrm{~cm}(2 \mathrm{in}$.) and over $5 \mathrm{~cm}(2 \mathrm{in}$.) in diameter.

\section{PETUNIAS (PETUNIA)}

Have separate classes for (a) plain single, (b) single ruffled and (c) double. Display the bloom only and use shallow containers (e.g. pie plate covered with foil with holes punched to accommodate the required number of blooms).

\section{SNAPDRAGONS (ANTIRRHINUM)}

Base classes on length of inflorescence or spike from top of spike to bottom floret.

(1) up to $15 \mathrm{~cm}$ (6 in.).

(2) 15 to $30 \mathrm{~cm}$ (6 to $12 \mathrm{in}$.).

(3) over $30 \mathrm{~cm}$ (12 in.)

Further breakdown into classes based on color or flower form is recommended. 


\section{ZINNIAS (ZINNIA)}

Base classes on flower size.

(1) under $4 \mathrm{~cm}$ (1.5 in.) diameter

(2) 4 to $8 \mathrm{~cm}$ (1.5 to 3 in.) diameter

(3) over $8 \mathrm{~cm}$ (3 in.) diameter.

Further breakdown into classes based on color or flower form is recommended.

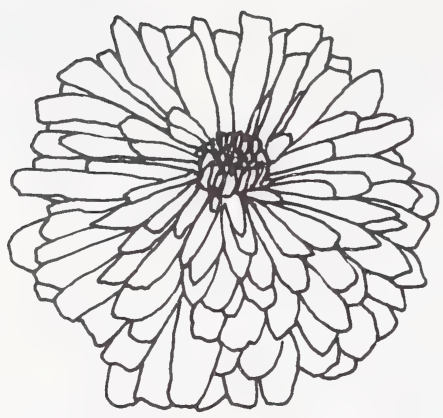

dahlia flowered

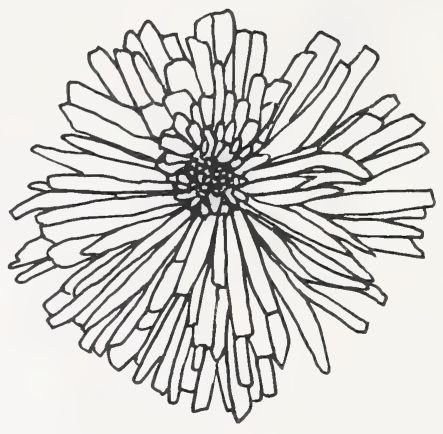

cactus flowered

\section{Standards of perfection}

Specific standards for perfection for each kind of cut flower commonly exhibited are not given. However, details are outlined for dahlias, gladiolus, roses and sweet peas.

\section{DAHLIAS}

Willis W. Collins ${ }^{3}$

Dahlias are classified by form or type and size. Form is determined largely by the shape and positioning of the "petal-like" ray flowers (see Glossary) The size classification for all flower forms is as follows:

AA (Giant) over $25 \mathrm{~cm}$ (10 in.) in diameter

A (Large) over $20 \mathrm{~cm}$ ( 8 in.) but under $25 \mathrm{~cm}$ (10 in.)

$\mathrm{B}$ (Medium) over $15 \mathrm{~cm}$ (6 in.) but under $20 \mathrm{~cm}$ (8 in.)

$\mathrm{BB}$ (Small) over $10 \mathrm{~cm}$ (4 in.) but under $15 \mathrm{~cm}$ (6 in.)

$\mathrm{M}$ (Miniature) up to $10 \mathrm{~cm}(4 \mathrm{in}$.) in diameter.

Other types:

$\mathrm{BA}$ (Ball) over $9 \mathrm{~cm}(3.5 \mathrm{in}$.) in diameter

M. BA (Miniature Ball) over $5 \mathrm{~cm}$ (2 in.) to $9 \mathrm{~cm}$ (3.5 in.) in diameter

$\mathrm{P}$ (Pompon) up to $5 \mathrm{~cm}$ (2 in.) in diameter

MS (Mignon Single) up to $5 \mathrm{~cm}$ (2 in.) in diameter.

${ }^{3}$ Member of American Dahlia Society, Inc. (Seattle, Wash.) 


\section{Form classification}

Formal decorative (F.D.) dahlias: Fully double flowers with the majority of the ray flowers (florets) broad, pointed or rounded at their tips, flat or slightly revolute, regularly arranged, and tending to recurve, the central rays cupped or spirally displayed.

Informal decorative (I.D.) dahlias: Fully double flowers with a majority of the ray flowers (florets) broad, pointed or rounded at their tips and tending to recurve; the ray flowers may be more or less laciniated; slightly revolute, twisted or curled, giving an irregular appearance to their arrangement; the central rays cupped and more or less spirally displayed.

Semi-cactus (S.C.) dahlias: Fully double flowers with the majority of ray florets revolute for at least half their length, pointed, and straight or slightly incurved or recurved; ray florets somewhat revolute but fully revolute for less than one-half their length.

Straight cactus (ST.C) dahlias: Fully double flowers with the majority of the ray florets revolute for at least half their length, pointed, and straight or slightly incurved or recurved.

Incurved cactus (I.C.) dahlias: Fully double flowers with the majority of the ray florets, fully revolute for at least half their length, pointed, and with a pronounced curvature toward the centre front of the flower head.

Ball (BA) dahlias: Fully double flowers, ball shaped or slightly flattened at the face, the ray florets blunt, rounded or indented, involute for most of their length, fully involute for about one-half their length, and normally displayed in a spiral arrangement.

Miniature ball (M.BA) dahlias: Same as ball dahlias, differing only in size.

Pompon (P) dahlias: Fully double flowers similar to ball dahlias but more globular and smaller in size; the ray florets involute for the whole of their length and fully involute for more than half their length.

Waterlily (WL) dahlias: Fully double flowers characterized by large, broad and generally sparse ray florets which are straight or slightly incurved giving the flower a flat appearance; the depth normally not more than half the diameter of the flower head.

Peony-flowered $(\mathrm{Pe})$ dahlias: Open-centred flowers with two or more rows of ray florets surrounding a disc. Some or all of the ray florets in the row adjacent to the disc may be irregularly formed, smaller, curled or twisted.

Anemone-flowered $(\mathrm{An})$ dahlias: Flowers with one or more rows of ray florets surrounding a dense group of colored elongated disc florets.

Collarette $(\mathrm{Col})$ dahlias: Open-centred flowers with one row of compound ray florets surrounding a disc. The outer part of the ray florets usually flat or slightly cupped; the inner parts, commonly called petaloids, generally multiple and irregular, forming a collar around the disc.

Single (S) dahlias: Open-centred flowers with one row of ray florets surrounding a disc.

Mignon single (MS) dahlias: Single dahlias under $5 \mathrm{~cm}$ (2 in.) in diameter on plants approximately 30 to $45 \mathrm{~cm}$ (1-1.5 ft) in height.

Orchid-flowered $(\mathrm{O})$ dahlias: Open-centred flowers with one row of ray florets surrounding a disc; the ray florets involute for two-thirds or more of their length with margins meeting or overlapping for some portion of their length.

Novelty (N) dahlias: Flowers not meeting any of the preceding descriptions.

\section{Merits}

Fresh, clean flower heads having a clean, bright color. Ray flowers all formed the same and of good substance; distance between ray flowers the same; flower heads true to type on a well proportioned (length and diameter) stem. Flower head facing at $45^{\circ}$ angle except in Ball, Miniature Ball and Pompon types. Shown at peak of development, centre full and tight in fully double forms. The first set of leaves beneath the flowerhead should be left attached. 


\section{Scale of Points}

$\begin{array}{lrr}\text { Color } & 20 \\ \text { Form } & 20 \\ \text { Substance } & 15 & \\ \text { Size } & 12 & \\ \text { Stem } & 10 & \\ \text { Foliage } & 10 & \\ \text { Bloom Position } & 4 \\ \text { Uniformity } & 4 & \\ \text { Distinction } & 5 \\ \text { Total } & 100\end{array}$

\section{Faults}

Flower head with different type ray flowers irregularly spaced; substance gone; back ray flowers drooping or soft; centre open; not symmetrical; bearded badly; too small or too large for size classification. Lack of uniformity in size, color and form. Stem too long or too short. The presence of a bud will disqualify the entry.

Types of dahlia flowers:
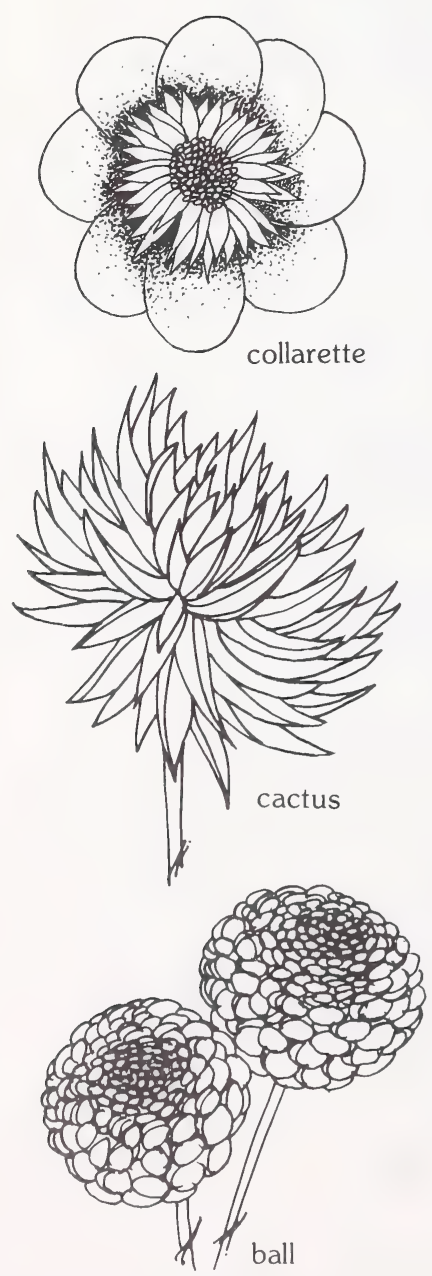
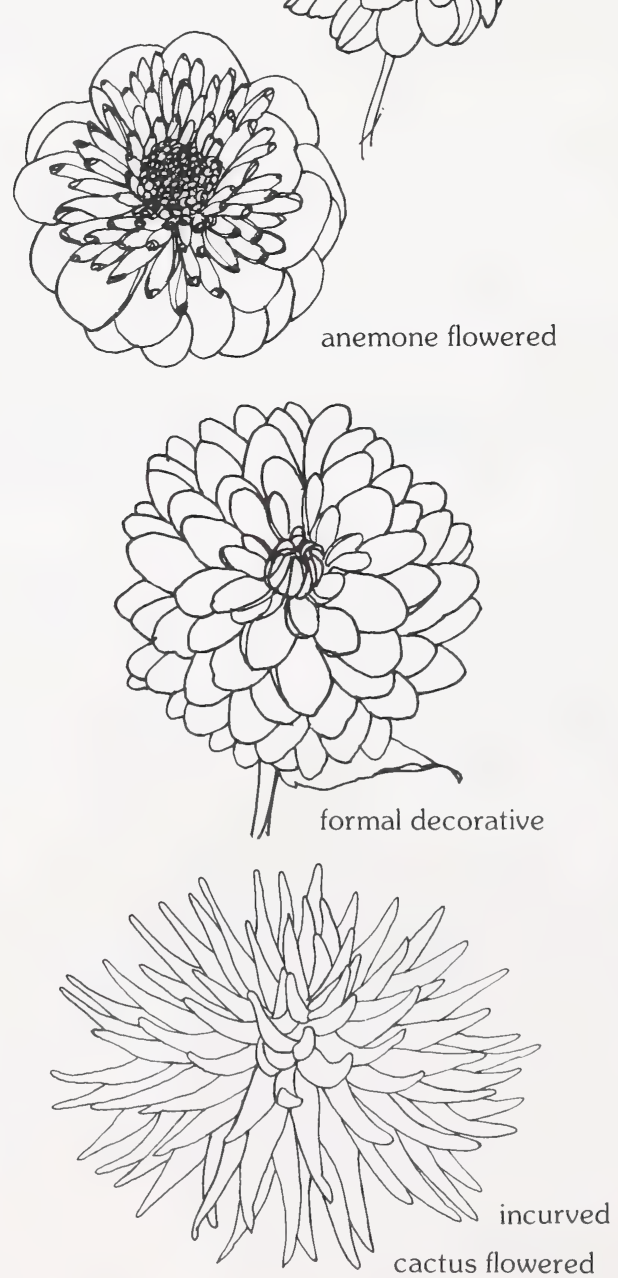
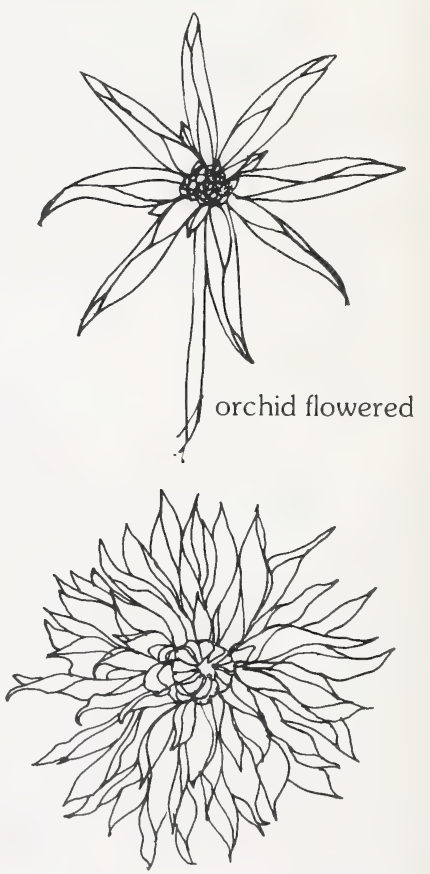

informal decorative

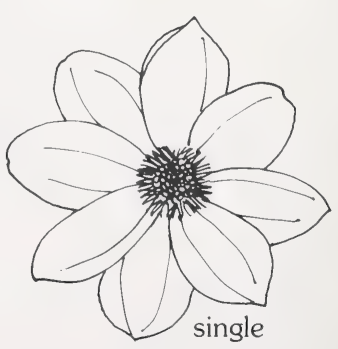




\section{GLADIOLUS}

The North American Gladiolus Council has published detailed information on judging standards for gladiolus. A summary of these standards is given below.

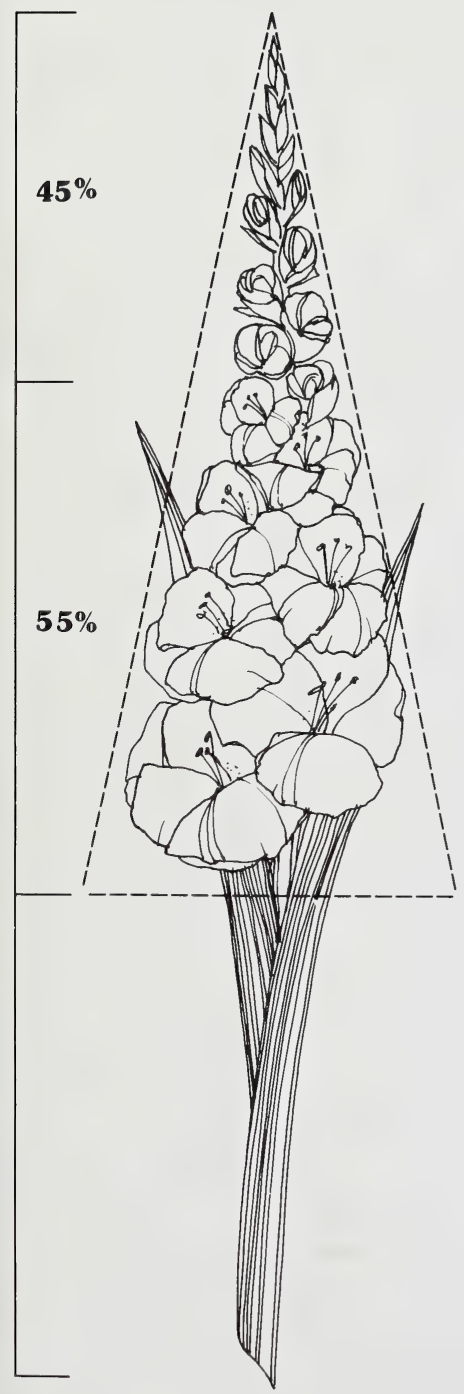

ideal inflorescence

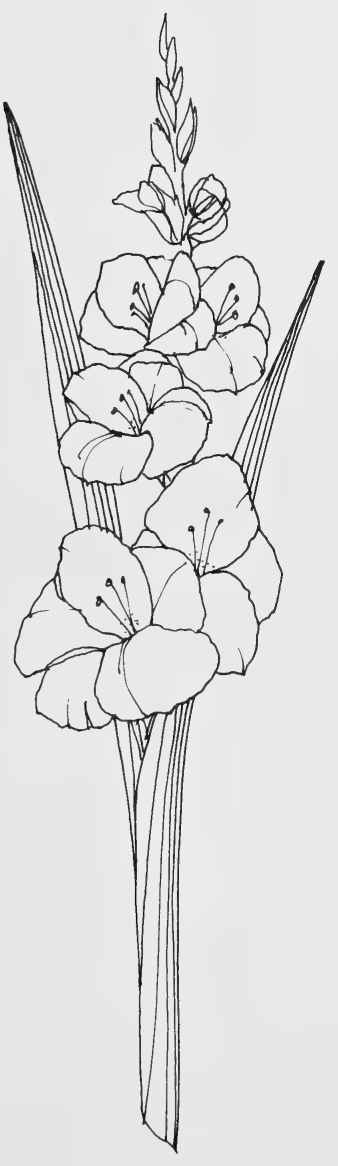

short stem, short head, poor spacing
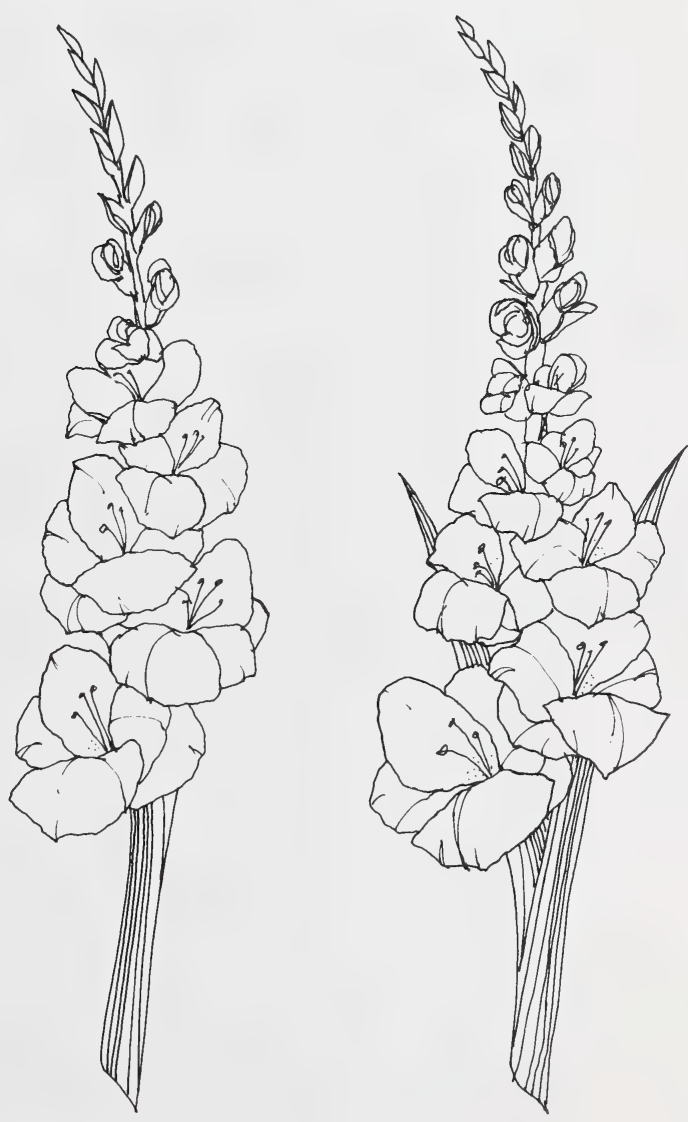

crooking, short stem, no foliage crooking, short stem, poor placement of bottom floret 
North American Gladiolus Council Score Sheet

Basic

Data

100:

200:

300:

400:

500:
Diameter

up to $65 \mathrm{~mm}$ (up to $2.5 \mathrm{in}$.)

65 to $90 \mathrm{~mm}$ (2.5 to $3.5 \mathrm{in}$.)

90 to $115 \mathrm{~mm}$ (3.5 to $4.5 \mathrm{in}$.)

115 to $140 \mathrm{~mm}$ ( 4.5 to $5.5 \mathrm{in}$.)

Over $140 \mathrm{~mm}$ (over 5.5 in.)
Total

Buds

15

18

19

20

19
Open

Florets

5

6
Buds in

Color

Stem Length

$443 \mathrm{~cm}$ (17 in.)

$546 \mathrm{~cm}(18 \mathrm{in}$.

$5 \quad 51 \mathrm{~cm}(20$ in. $)$

$651 \mathrm{~cm}(20$ in. $)$

$5 \quad 56 \mathrm{~cm} \mathrm{(22} \mathrm{in.)}$

\section{SCORE CARD}

\section{Floret}

Color (30 points)

1. Clarity

2. Saturation

3. Harmony

4. Uniformity of color

5. Overall beauty and appeal

Structure (10 points)

6. Floret form

7. Substance and texture

\section{Spike}

Structure (40 points)

8. Total buds

9. Open florets

10. Buds in color

11. Attachment

12. Facing

13. Uniformity of florets

14. Stem

15. Grooming

Balance (20 points)

16. Floret size to flowerhead

17. Inflorescence to flowerhead

18. Taper

19. Distinctiveness

TOTAL (100 points)

Less additional deductions

FINAL SCORE

ONE SPIKE

\section{Exhibition \\ Cultivars}

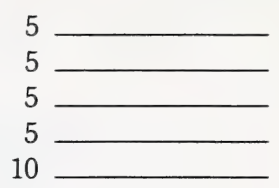

5
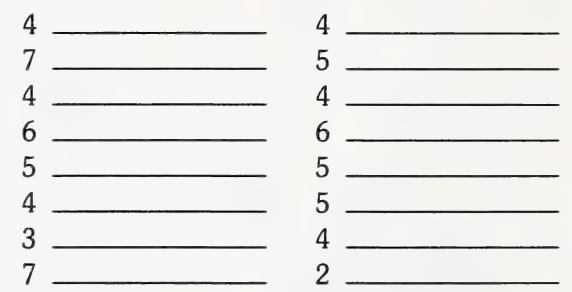

8
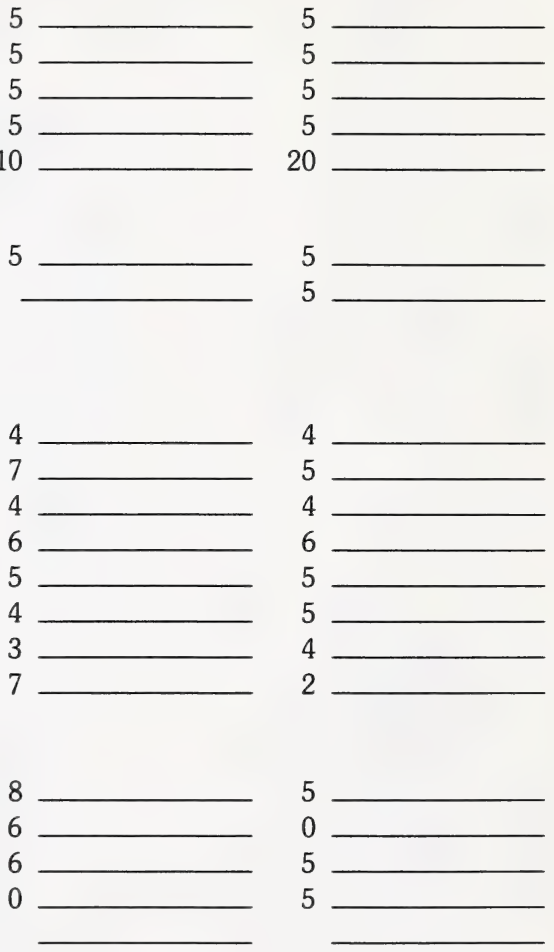

5

5

Seedling

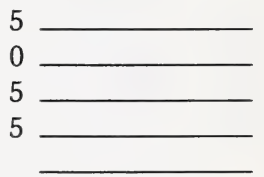

\section{PENALTIES - DEDUCTIONS}

Item:

8. -1 each bud short

9. -2 each floret short

10. -1 to -4 judge's opinion

16. -2 for each $2.5 \mathrm{~cm}$ (1 inch) over or under

17. -2 for each $2.5 \mathrm{~cm}$ (1 inch) over or under 
Additional deductions (up to 10 points for each item):

Crooking

Condition

Health

Deformed florets

Adventitious buds

Irregular opening

Total additional deductions

\section{Three-spike and five-spike judging}

In three-spike and five-spike competitions individual spikes are judged under the single-spike system and scores are averaged to account for 85 per cent of the total points. The remaining 15 percent of the points are awarded for the matching quality of the spikes.

Average score

Bonus for uniformity

FINAL SCORE 3 \& 5 SPIKE

$(100 \%)$

\section{Standards of perfection}

1. CLARITY of color. Deduct for dullness, muddiness, distractive flecking and the smearing of vagrant color.

2. SATURATION of color. Deduct for feathering, peeling, unevenness, bleeding of blotches and transparency denoting lack of pigment.

3. HARMONY. Deduct for objectionable throat or lip markings, bizarre or discordant blotches, detracting anther or calyx coloring.

4. UNIFORMITY of color. Deduct for fading or difference of color from one floret to the next, in whole or in part. This includes blotches or other markings which shall be uniform.

5. BEAUTY and APPEAL. Impact of color and/or form on the judge. This is purely subjective with the judge, but one should strive not to permit the frequent appearance of the cultivar to cloud appreciation of its beauty, or the novelty of a new one to bedazzle. Beauty and appeal are of primary importance in the selection of new introductions, regardless of types, thus these factors deserve extra weight in the judging of seedlings.

6. FLORET FORM. Deduct for cupping, hooding, clawing, uneven throat knuckling, folded petals, excessive reflexing or ragged effect. Should be penalized only if form is definitely displeasing, not because it may be unusual.

7. SUBSTANCE. Thickness of petals, which usually denotes keeping quality, resistance to handling and reduced hydration.

TEXTURE - The physical surface quality of the petals. A velvety surface or sparkling sheen add to beauty - a rough, dull surface detracts.

8. TOTAL BUDS. This includes open and partly open florets. Deduct for too few under Basic Data and Penalties and Deductions. There is no penalty for too many buds except as it affects items 16 and 17.

9. OPEN FLORETS. A floret shall be considered open if it is one half or more open. Deduct for too few under Basic Data and Penalties and Deductions.

10. BUDS in COLOR. Deduct one point for each bud in color short of Basic Data reqirements. Deduct a maximum of two points for too many in color when objectionable. Flowerheads with a great many buds and open florets may exceed the norm in buds in color without penalty. 
11. ATTACHMENT. Deduct for a split calyx or elongated tube which allows a floret to droop unattractively and increase danger of floret loss with handling. This characteristic is inherent in some cultivars.

12. FACING. Deduct for improper facing, stem showing through wide-open florets, reversed florets or buds and face-up florets unless uniform. Downward nodding florets also deserve a penalty.

13. UNIFORMITY of FLORETS. Deduct for a mix of single and double lip petal floret types on any spike. Florets should be of proper size to conform with their placement on the flower head. There should be a gradual decrease in the size of each floret on the spike from the bottom upward. There should be no variance in degree of rotation.

14. STEM. The length of stem is usually set by the show committee. Anything less, and stems too heavy or too weak for the size of the floret and flowerhead should be penalized. When practical, show committees are encouraged to allow $43 \mathrm{~cm}$ (17 in.) stems for the 100 size; $46 \mathrm{~cm}$ ( $18 \mathrm{in}$.) for $200 ; 51 \mathrm{~cm}$ ( $20 \mathrm{in}$.) for 300 and 400 ; and $56 \mathrm{~cm}$ ( $22 \mathrm{in}$.) for 500 size to give balanced spikes.

15. GROOMING. The presentation of the spike on the show table. There should be only a one-point penalty for the removal of the bottom floret to indicate that it was inferior to the spike even though its removal improved the spike. However, penalize four points for the removal of any portion of floret or calyx of the second floret, and a total of five points if the bottom two florets are missing. An additional two points is available for deducting in case of any further infraction. Deductions should be made for a poorly dressed spike that allows fallen pollen to remain, or florets to overlap those above. Side shoots must be removed from all but seedling entries, but a penalty of two points should be applied if the shoot sheath is removed. Tip buds broken off or foreign material such as pins or cotton balls left in place disqualify the spike from competition.

16. BALANCE OF FLORET SIZE TO FLOWERHEAD. The length of the flowerhead should be between five and six times the breadth of the inflorescence at its widest point. Any variance above or below this ratio should be penalized as indicated under Penalties and Deductions. The important thing here is the horizontal mass, so allowance should be made for cultivars with flaring or needlepoint florets, the measurement of which may not truly reflect this factor. Deduct for irregular spacing which allows gaps in the symmetry of the spike, and for crowding which allows a floret to hide the throat of the floret below.

17. BALANCE OF INFLORESCENCE TO FLOWERHEAD. Inflorescence is the continuous mass of color made by the open and half open florets. It should be from 50 to 55 per cent of the overall length providing that the spike is not thrown out of balance. (Depends on the width and flatness of the florets.) Six points are allowed for this item on the exhibition side of the score sheet because of its relative importance to the symmetry of the flower head. No deduction for overbloom should be made on seedlings, since anything beyond the required minimum number of open florets is a factor to be desired.

18. TAPER. This should be gradual from the bottom floret to the spike tip including the green buds. From the half open florets to the tip there should be a gradually reduced separation, a lowering and a movement of the buds to alternate sides. Deduct for a clump of unseparated buds at the tip. The transition of color from the open florets to the green buds should taper gradually and not square off abruptly. The bottom of the flowerhead should be rounded.

19. DISTINCTIVENESS. An attractive variation in color, floret form or spike conformation which might tend to broaden interest in or the use of glads in general. This item is a plus factor which applies only to seedlings.

Additional Deductions - Deduct up to 10 points for each of the following:

CROOKING - Penalize in proportion to the impairment of flowerhead attitude or the usability of the spike.

CONDITION - Deduct for lack of freshness in any part of the florets or foliage. Deduct here also for calyx burn, foliage tip burn, insect or mechanical damage.

HEALTH - A spot of fungus on a petal could entail a one or two point deduction depending on how it affects the whole spike. Flowers or foliage spotted all over with 
disease should be disqualified. Deduct here also for discoloration in foliage stem or calyx which indicates a probable nutritional deficiency.

DEFORMED FLORETS - Not to be confused with petal folding which is covered in Item 6. Deduct in proportion to severity.

EXTRA BUDS (or double buds) - Are usually shaved off by the good showman, providing another reason for the judge to look at the spike from the rear. One shaved off bud which does not mar the appearance of the spike probably deserves a one or two point deduction. A number of them, either shaved off or left in place, increases the penalty.

IRREGULAR OPENING - Seriously affects the balance and taper. Penalty should be in proportion to the harm done.

\section{Baskets, Vases and Patinas}

Suggested points for scoring. (Total 100 points).

$\begin{array}{llll}\text { Arrangement } & 40 & \text { Color harmony } & 10 \\ \text { Condition } & 15 & \text { Conformity } & 10 \\ \text { Quality } & 15 & \text { Use of foliage } & 10\end{array}$

A basket is an arrangement or display of glads for effect. The arrangement may be made in a basket or flared container. The overall finished effect should be wide and full. Only enough terminal buds may be removed to make a symmetrical picture. (From not more than 25 per cent of the total number of spikes.)

\section{Arrangement}

Top line of basket high in centre, gradually tapering to the sides to make a symmetrical curved semi-circle. Each spike should be able to be seen clearly. Spikes in front should not hide those in the rear. Spikes should be arranged from back to front to make a gradual full effect.

\section{Condition}

All florets should be clean and fresh. Penalize for the removal of more than two bottom florets.

\section{Quality:}

Spikes should be well grown and of good quality. No penalty for well grown material. Penalize for undersize, also for thrips marks, burning, excessive spray residue or side shoots not removed. We would like to see a severe penalty in the display class for 100 s and 200 s grown oversize, with permission for judges to either disquality or place in higher size classes.

\section{Color harmony:}

Under this heading the single spikes should be judged as well as the color harmony of the finished arrangement. Since so many seedlings are shown in the display classes, we should be extra careful in our judging of these entries. We are not against this practice, but think that the standard should be just as rigid here as in the open classes, as far as color and harmony are concerned. The overall effect should be appealing as to color and harmony.

\section{Use of foliage:}

Foliage should be in good condition but be secondary, at least, to the flowers. It should not compete with, but rather enhance the flowers. The effect of the foliage should be fine to medium in weight and appearance depending on the class of glads with which it is to be used. 100 and 200 glads should have a finer type foliage than the larger glads. It may be a good idea to stipulate that foliage should be plain as opposed to berried or flowered. Variegated could be permitted where it does not detract from the arrangement or is not too conspicuous. Avoid use of material that is on the conservation list.

\section{Conformity:}

Entry should contain the number of spikes called for in the class. Penalize for more than 25 per cent of terminal buds removed on total number of spikes. 


\section{LILIES}

Unlike Gladiolus the genus Lilium is judged with little emphasis put upon the number of flowers which are open. A stem with but a single open flower in perfect condition will surpass one with more flowers open but not all in prime condition. A judge must be familiar with the various species to know the number of flowers and buds to be expected with each kind.

Lilies should be shown in classes based upon the following classification system:

Division I - The Asiatic Hybrids: Hybrids and cultivars derived from such species or hybrid groups as $L$. tigrinum, $L$. cernuum, $L$. davidii, $L$. pensylvanicum ${ }^{*}$, $L$. leichtlinii var tigrinum ${ }^{* *}$, L. amabile, L. pumilum and L. bulbiferum.

Ia: Flowers upfacing

Ib: Flowers outfacing

c: Flowers pendant (down-facing)

*Formerly L. dauricum

** Formerly L. leichtlinii var. maximowiczii.

Division II - The Martagon Hybrids: Hybrids and cultivars derived from such species or hybrids of $L$. martagon and $L$. hansonii.

Division III - The Candidum Hybrids: Hybrids and cultivars derived from $L$. candidum, $L$. chalcedonicum, $L$. monadelphum and other related European species such as $L$. testaceum, but excluding L. martagon.

Division IV - The American Hybrids: Hybrids of American species.

Division V - The Longiflorum Hybrids: Hybrids and hybrid cultivars of L. longiflorum and L. formosanum.

Division VI - The Trumpet and Aurelian Hybrids: Hybrid trumpet lilies and Aurelian Hybrids derived from Asiatic species, including $L$. henryi, but excluding those derived from $L$. auratum, $L$. speciosum, $L$. japonicum and $L$. rubellum.

VIa: Chinese trumpets. Contains all true funnel-form hybrid cultivars and hybrids derived from $L$. leucantheum, $L$. centifolium, $L$. sargentiae and $L$. regale.

VIb: Bowl-shaped Aurelian hybrids.

VIc: Pendant Aurelian hybrids.

VId: Sunburst Aurelian hybrids.

Division VII - The Oriental Hybrids: Hybrid cultivars or hybrids of $L$. speciosum, $L$. auratum, $L$. japonicum, $L$. rebellum and to include any of their crosses with $L$. henryi.

VIla: Trumpet-shaped flowers

VIIb: Bowl-shaped flowers

VIIc: Flat-faced flowers

VIId: Recurved flowers

Division VIII - Miscellaneous Hybrids: All hybrids not provided for in any previous division.

Division IX - Lily Species: Contains all true species and their botanical forms.

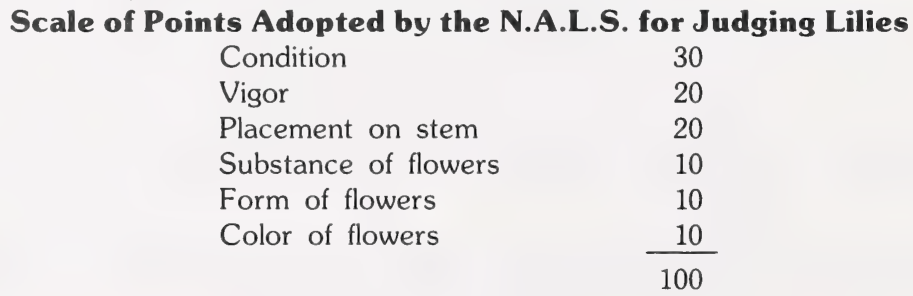



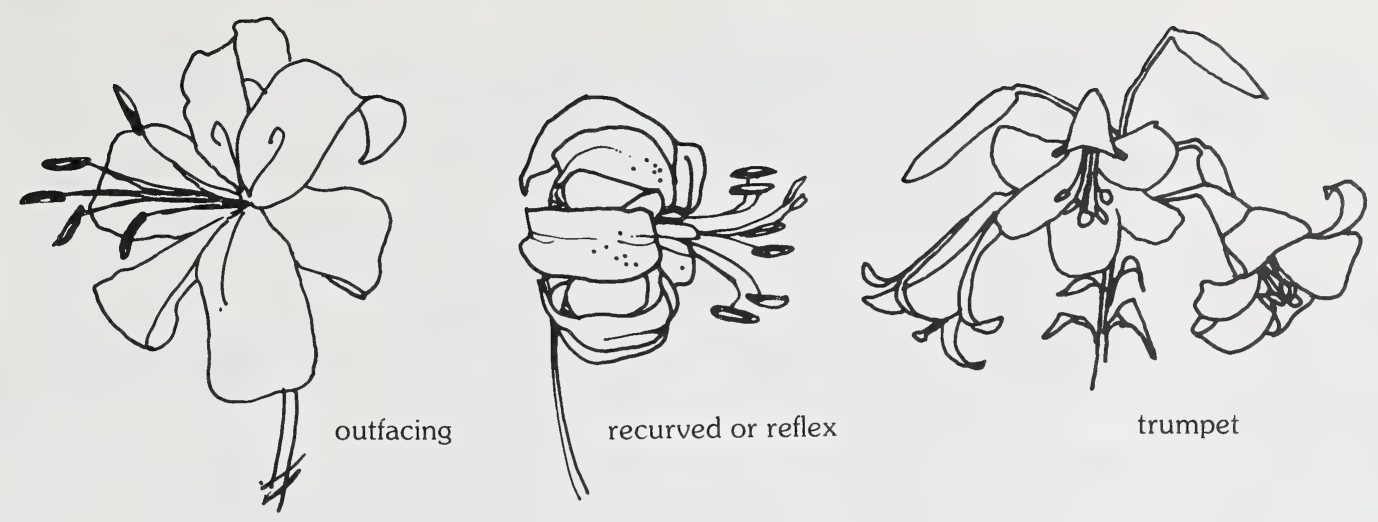

trumpet
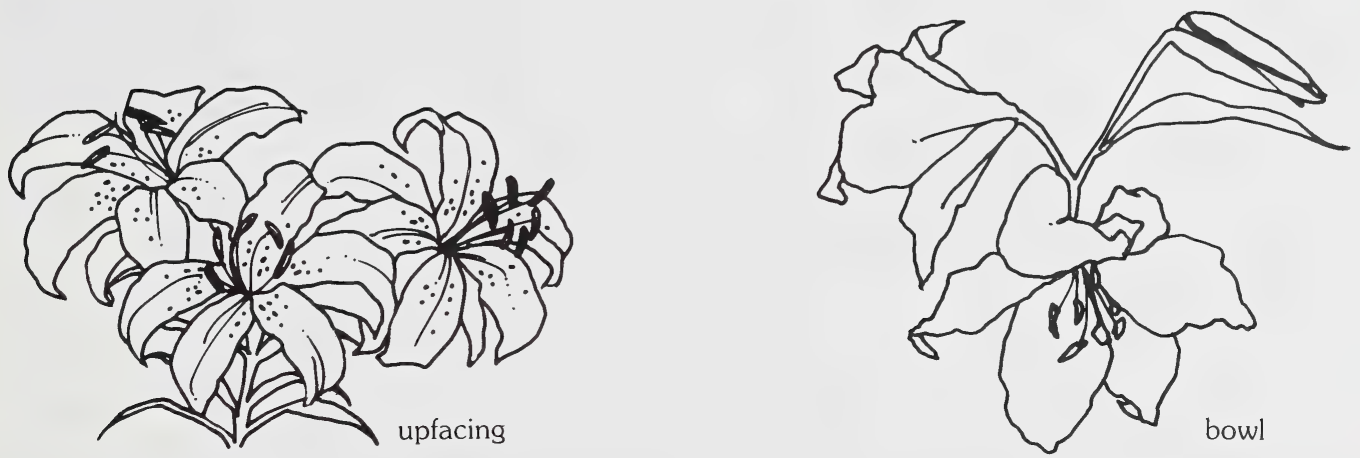

\section{ROSES}

\section{Notes to exhibitors}

Hybrid tea and hybrid perpetual specimen blooms should be grown disbudded for show purposes, but the polyanthas, floribundas and grandifloras are best exhibited as naturally grown flowers without disbudding except for removal of crown buds. The former types are exhibited as specimen blooms and the latter as sprays. All singleflowered cultivars are best exhibited as naturally grown. Any of the above types may be exhibited in a specimen bloom class provided they are disbudded. Miniatures may be exhibited as a single stem, a spray or single bloom (e.g., box classes).

Separate classes should be set up for exhibiting the so-called "species" and "shrub" roses. These are best exhibited as naturally grown without disbudding.

Disbudding of the hybrid teas and perpetuals (including their climbing forms) consists of pinching out the tiny side buds with thumb and finger as early as possible in their development. Removing these buds in their early stages will leave no scars. Roses showing evidence of recent disbudding will lose points in judging. However, failure to disbud exhibits in specimen classes will disqualify an entry, since side buds count as extra blooms. 
Good grooming is very important, especially for specimen blooms. A blemished petal may be deftly removed before exhibiting, if doing so does not destroy the character of the bloom. Petals may be arranged a little better through the careful use of a small camel-hair brush or other such instrument. No amount of grooming, however, can compensate for poor quality blooms.

The stage at which a rose should be cut for exhibition purposes is difficult to state. It depends partly on the weather, which affects the rate at which a rose will open and how long it will last as a cut flower. Normally, roses are cut the day before exhibiting, to allow hardening. However, sometimes they are cut several days in advance and stored dry in pliofilm packages at 1 to $2^{\circ} \mathrm{C}$. The important factor is that the blooms be of top quality and at the proper stage of maturity at the time of judging.

\section{Judging standards}

Merits: specimen exhibits - Freedom from spray or dust residues, and disease or insect injury; clean, healthy foliage; bloom half to three-quarters open (single blooms fully open); symmetrical in outline, with a well formed centre; color fresh and brilliant according to variety; good substance; stem adequate to hold bloom upright and of a length and thickness to be in proportion to bloom; thorns left undisturbed.

Merits: spray exhibits - Same points apply as for specimen bloom; as well as balanced spacing of blooms, with a good number of flowers in prime stage of development and remaining buds in graduated stages of development.

Defects: Failure to disbud specimen bloom or evidence of recent disbudding; blemished petals, blooms opened past their prime, poor substance, lack of freshness; dirty or unhealthy foliage; lack of adequate foliage for the bloom; thorns removed.

\section{Score}

\begin{tabular}{lr} 
Form & 25 \\
Color & 20 \\
Stem and foliage & 20 \\
Substance & 15 \\
Balance and Proportion & 10 \\
Size & 10 \\
\cline { 2 - 2 } \multicolumn{1}{c}{ Total } & 100
\end{tabular}

\section{Hybrid tea exhibition specimens}

Must be shown without evidence of a side bud having been present. The failure to disbud is a very serious fault and is cause for disqualification.

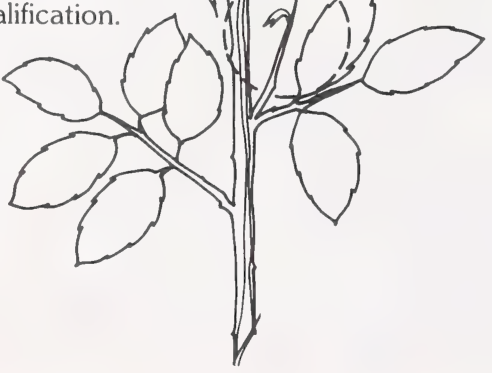

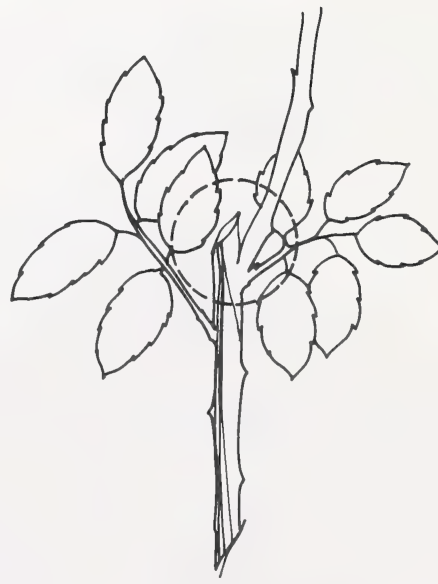

This stem-on-stem condition is cause for disqualification. The primary stem should not have a portion of previous stem growth attached. 


\section{Floribundas}

The flower spray should form a regular outline without gaps or unusual spaces as in A and B. Sprays can be domed as in B or flat as in C. In C the flowers present a uniform arc. Spent blooms can be eliminated to create such an appearance, although there is a penalty. D shows a faulty spray with an irregular appearance. Flowers that are too long or too short should be removed. Deduct points depending on how well the growth is removed. Leaving the growth incurs an even greater penalty.

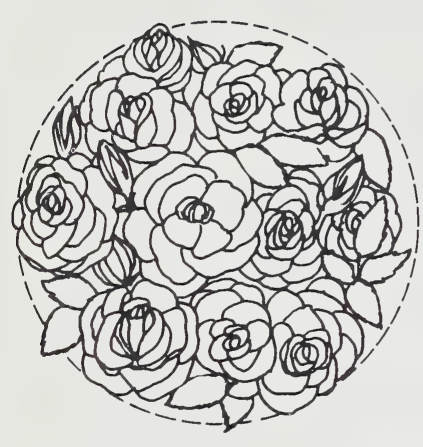

A
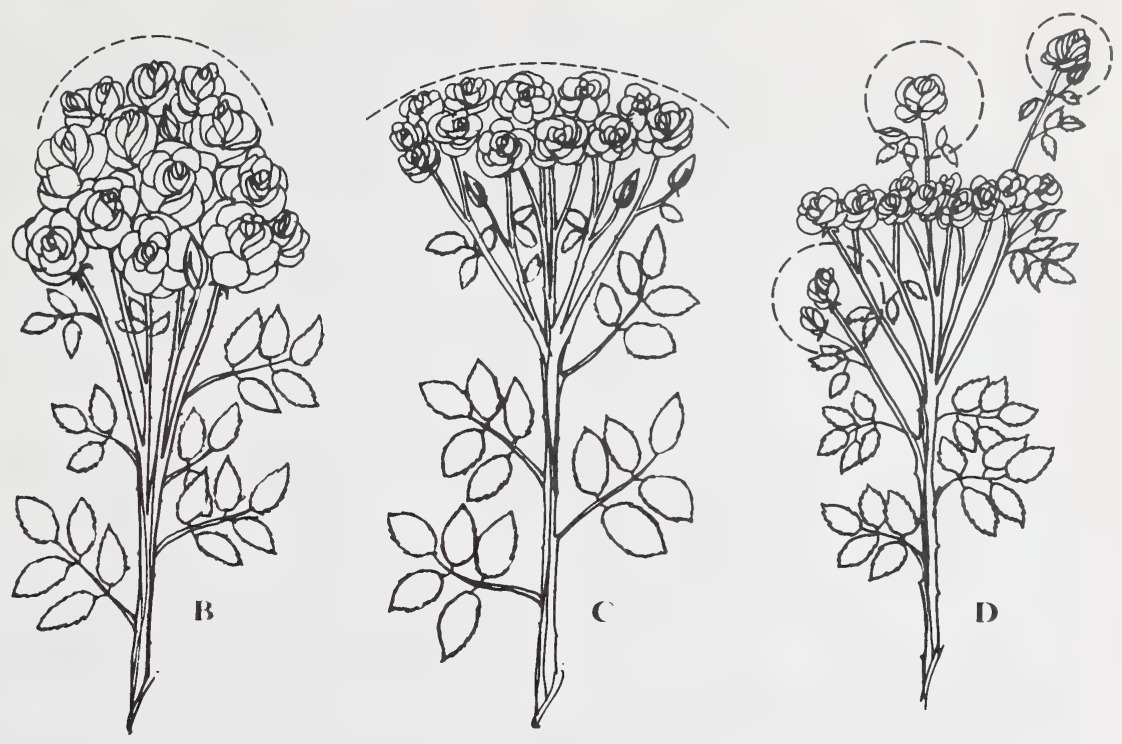

\section{Single specimen roses}

Top view $A$ and two sides views ( $B$ and $C$ ). A shows the ideal flower form. Flowers should be symmetrical as in $B$ and $C$, unfurling from the apex as shown. Flower should be one-half to one-third open with the outer row of petals forming a line at right angles to the calyx tube. Some cultivars however characteristically have their outer row falling below this line as in $\mathrm{C}$. D shows a single specimen with a faulty centre (balled, confused and split)
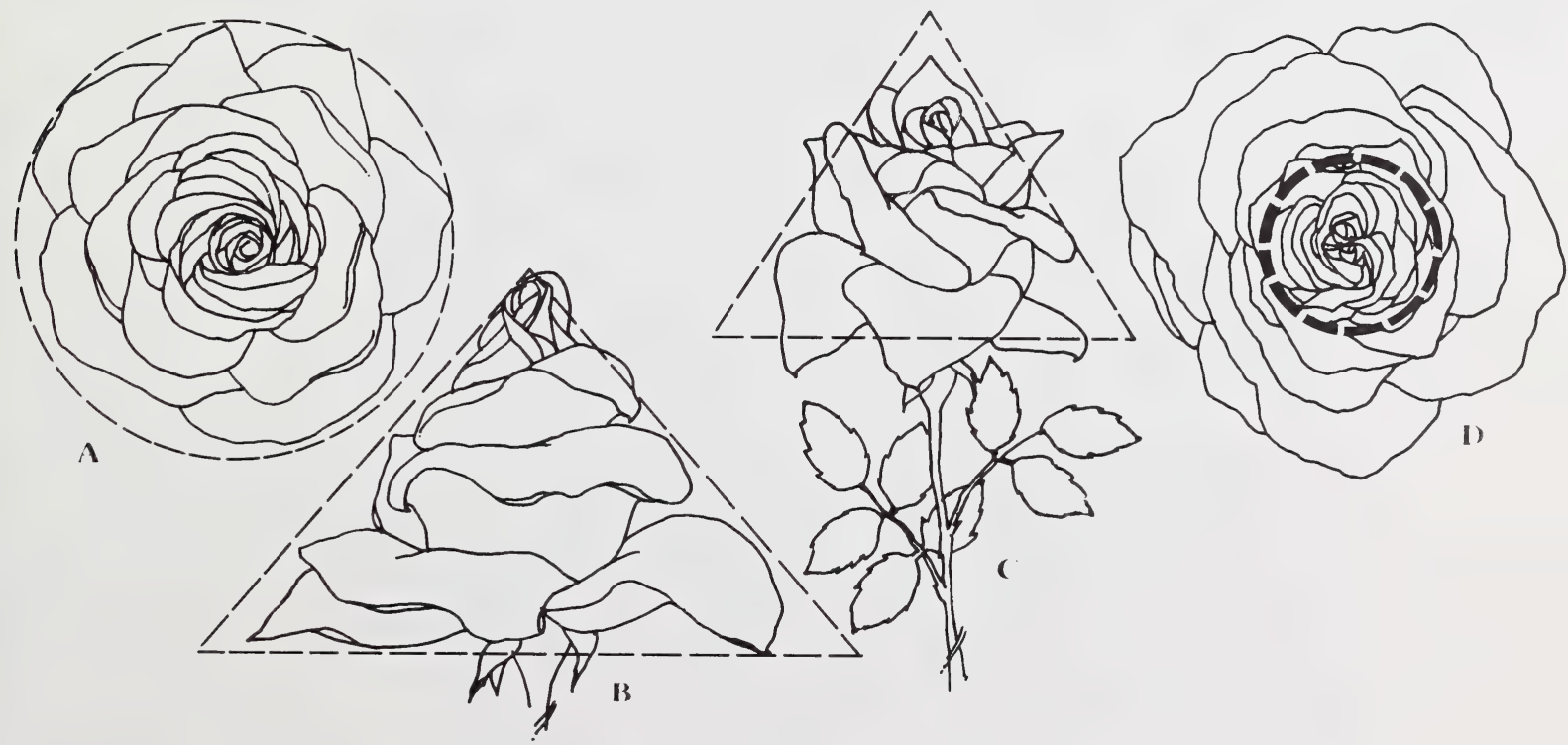


\section{SWEET PEAS}

A sweet pea bloom consists of five petals but these appear as three distinct structures known as the standard, wings and keel.

\section{Merits}

The standard or rear petal should be large, erect, of good substance, well waved or frilled, and of the same size and shape as the standards of other blooms on the spike.

- The two wings or side petals should be of good substance, uniform in size and shape, and with a slight separation between them.

- The keel, consisting of two fused petals enclosing the seed apparatus, should be tightly closed.

- An ideal stem or spike of the Spencer cultivars has a total of four or five blooms all large, well waved, of similar size, fully open and evenly arranged. Other cultivars should have as many as possible of the total number of blooms on a spike fully open, with the topmost fully open bloom comparable in size to the bottom one.

- Blooms should all face in one direction, be absolutely fresh, clean and of the color typical of the variety or cultivar.

- The total length of the spike should be in proportion to the flower head. For an average spike this length would be about $38 \mathrm{~cm}$ ( $15 \mathrm{in}$.) but a large spike with five blooms could be as long as $45 \mathrm{~cm}$ (18 in.).

- Diameter of the stem is also important in relation to the overall spike. The stem should appear strong but not coarse in relation to the flower head.

The more fully open blooms that a spike contains, the better, but a good three-bloom spike is better than a mediocre four, and a good four better than a mediocre five.

\section{Defects}

- Overlapping wings, folded standards, wings or standards tucked into keel, or an open keel; blotchy, streaky or muddy color, greening at edge of petals; immaturity of top bloom or, more serious, fading and withering of lowest bloom (blooms removed from top or bottom of flower head must be considered immature or faded); improper facing of blooms; large gaps between blooms (overlapping of blooms is less of a fault); crooked or twisted stems, (but not those with a slight uniform curve).

\section{Score}

Condition, substance and color of blooms

Form and placement of blooms $\quad 25$

Size and number of blooms 20

Length and condition of stem 15

Effectiveness of staging, color harmony and fragrance

Total

$\frac{10}{100}$

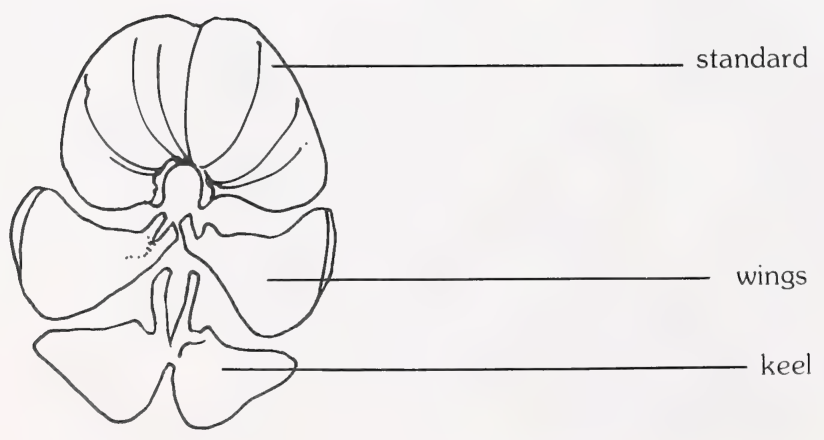




\section{Collections and displays}

Shows may have classes for collections or displays of cut flowers or perhaps collections or displays combining cut flowers with fruits and vegetables. For detailed comments on such classes see pages - (Fruits) and -(Vegetables). For definitions of "collection" and "display" see Glossary.

\section{Bouquets and vases of flowers}

Although flowers displayed as bouquets in vases require a certain amount of arranging they do not constitute floral arrangements unless each unit is placed to produce a design (see Glossary). Good taste in choice of cultivars and color is necessary. Colors should harmonize effectively. The purpose for which the bouquet is made should be stated. Baskets (see glossary for definition).

\begin{tabular}{lr}
\multicolumn{2}{c}{ Score } \\
Condition & 30 \\
Color harmony & 25 \\
Proportion and balance & 20 \\
Suitability for purpose indicated & 15 \\
Originality & 10 \\
\cline { 2 - 2 }$\quad$ Total & 100
\end{tabular}

\section{Floral arrangements}

The making of floral arrangements has been defined as "the art of organizing elements according to the principles of design to attain beauty, simplicity, expression and harmony". In floral arrangements, the container and any accessories (figurines, candlesticks, etc.) are an integral part of the arrangement.

In setting up floral arrangement classes, the show committee should specify what materials may or may not be used. Fresh, dried or artificial flowers may be used unless a particular type is specified. Although most people would agree that fresh flowers should be required for floral arrangement classes at horticultural shows, restrictions should not be placed on the use of foliages or background flowers, such as baby's breath. Such materials as cotoneaster, nanking cherry, peony, goutweed and sprigs of juniper can be tastefully incorporated into floral arrangements.

Emphasis should be placed on arrangements suitable for use in the home; for example, a centre piece for dining room table or kitchen table; arrangement suitable for bedroom, living room, coffee table, end table or television set; arrangements suitable for special occasions, such as birthdays and anniversaries. Classes may be provided for arrangements using only dried ornamentals. The use of weeds in either dried or fresh condition should be avoided. Both Noxious and Restricted weeds as designated in the Weed Control Act (see Appendix I) must not be used in flower arrangements whether dried or otherwise. However, they may be included in dried and pressed displays or collections if they are correctly identified.

\begin{tabular}{lc}
\multicolumn{1}{c}{ Score } & \\
Design & 25 or $(20)$ \\
Color harmony & 25 or $(20)$ \\
Originality & 20 or (15) \\
Suitability to occasion or & \\
purpose (if stated) & $(15)$ \\
Texture harmony of materials & 10 \\
Relation to container & 10 \\
Condition of flowers and foliage & 10 \\
\cline { 2 - 2 }$\quad$ Total & 100
\end{tabular}


Corsages are in effect a special type of floral arrangement. Therefore the principles outlined under FLORAL ARRANGEMENTS apply and a similar scoring system can be used. Instead of points being awarded for the container and accessories and how they relate to the overall arrangement, these points can be applied to the skillful execution or mechanics of the corsage (neatness and finished appearance to the back or underside). The following items must be taken into account in both the making and judging of a well designed corsage:

1. Must include both flowers and foliage in a balanced and pleasing proportion.

2. Must be sturdy. The judge may wish to pick it up to check for sturdiness and skill of execution.

3. Must be lightweight.

4. No wire should show. All wire must be wrapped neatly but with as little floral tape as possible in order to reduce bulk and weight.

5. Must include a corsage pin to look completed.

6. Should include a ribbon.

7. May be placed in an unsealed plastic bag to help retain freshness.

\section{Shadow boxes, or niches}

In judging shadow boxes, or niches, the porportion of the composition to the dimensions of the box should always be considered first. These arrangements are compositions to be seen as a picture, with fixed boundaries. There is no point in exhibiting them unless this is understood. The size of the box can vary but often it is about $75 \mathrm{~cm}$ (30 in.) high, 45 to $60 \mathrm{~cm}$ (18 - 24 in.) wide and 30 to $45 \mathrm{~cm}$ (12 - 18 in.) deep.

If any part of the exhibit touches the sides or top of a niche or shadow box, points must be taken off by the judge.

\begin{tabular}{lr}
\multicolumn{2}{c}{ Score } \\
Overall arrangement (color, pro- \\
portion, and balance) \\
$\begin{array}{l}\text { Proportion of composition to } \\
\text { dimensions of box }\end{array}$ \\
$\begin{array}{l}\text { Lighting and shadows } \\
\text { Distinction and originality }\end{array}$ \\
$\begin{array}{l}\text { Suitability of combination of floral } \\
\text { materials with one another and } \\
\text { with accessories }\end{array}$ \\
$\begin{array}{ll}\quad \text { Total } & 15 \\
& 100\end{array}$
\end{tabular}

\section{Pot plants}

When accepting entries for the pot plant classes, the show committee should pay special attention to the health of the plants, disallowing any that show infestations of insects or are infected by diseases.

Hanging baskets containing a mixture of different kinds of plants should not be entered in pot plant classes containing single specimen entries. Such mixed baskets should only be exhibited in classes especially designated for them.

- Separate classes should be provided for foliage plants, flowering plants, cacti, and succulents. 
- Classes for "ferns" should be limited to true ferns only (does not include "Asparagus ferns").

- Plants grown for both their foliage and flowers (rare) may be exhibited in either category depending on the presence or absence of flowers and flower buds.

- All entries must be container grown, not merely dug up from a flower bed and placed in a pot just prior to the show.

\section{Judging standards}

- The presence of flowers on foliage plants should be considered a fault, whereas a plant normally grown for its attractive flowers should never be entered in a foliage class even when flowers are absent.

- A foliage plant by definition is grown and marketed as a plant with green or decorative foliage. If flowers are present, foliage quality is often poor.

- Plants for table decoration should be of moderate height (not more than $38 \mathrm{~cm}$ (15 in.) total height), well furnished (compact), well balanced, and of light and graceful habit.

- In both foliage and flowering plant classes, foliage should be clean, healthy, of good color, and free from any signs of disease, insect, or mechanical injury.

- Should be exhibited in clean, attractive pots.

- Plant size and pot size should be in proper proportion.

- Other factors being equal, preference is usually given to rarity of species or to species that are more difficult to grow (for example, Dieffenbachia vs. Coleus). For list of easily grown house plants see Garden Fax "Easy to Grow House Plants, Agdex 285/20-1".

- Bonus points could be given for correctly identifying the plant exhibited.

\section{Foliage plants}

\section{Standards of perfection}

Symmetrical and correct form for cultivar; strong and proportionate stem or stems; abundant, glossy green foliage or bright, clear, vivid-colored foliage according to the type; foliage free from residues* and from insect, disease, and mechanical damage; absence of flowers, proper proportion of pot to plant.

\begin{tabular}{lr}
\multicolumn{2}{l}{ Score - Specimen Classes } \\
Cultural perfection & 45 \\
Foliage & 30 \\
Size of plant and proportion to plant & 15 \\
Rarity & 10 \\
\cline { 2 - 2 } Total & 100
\end{tabular}

\section{Flowering plants}

\section{Standards of perfection}

Symmetrical development; proper proportion of pot to plant; lush foliage of color for cultivar; foliage and flowers free from blemishes; flowers borne toward centre above foliage; strong flower stems; clean flower color.

*residues include "cosmetics" such as plant shine or dormant oil products. 


\section{Score - Specimen classes}

Cultural perfection

Floriferousness

Size of plant and proportion to

pot

Color of bloom 10

Foliage 10

Rarity $\quad \frac{10}{100}$

Total

100

Score - Collection or group classes for foliage or flowering plants

Cultural perfection 40

Arrangement 30

Number of kinds or cultivars

and rarity 25

Size of collection $\quad 5$

Total 100

\section{AFRICAN VIOLETS}

Single crown - symmetrical with minimum of gaps when viewed from above; appearing as a shallow dome from the side, (some cultivars have leaves that cascade down over pot however); lateral shoots, with or without accompanying whorl of leaves, upset the symmetry and should be severely faulted. Multiple crown plants are not recognized as plants worthy of exhibition by African Violet Societies. Therefore classes for multiple crown plants are not recommended.

\section{Standards of perfection}

- Size of plant is not as important as freshness and symmetry.

- Plants should be in the centre of the pot.

- Plant size and pot size should be in proper proportion.

- Entries with supports, or collars under the foliage or in pots with flared tops should be disqualified.

\section{Score - Specimen classes}

Leaf pattern or form

Floriferousness (typical of cultivar)

Condition

Size of bloom (typical of

cultivar)

Color of bloom (typical of

cultivar)

Total

$\frac{10}{100}$

\section{CACTI AND OTHER SUCCULENTS}

All cacti, with minor exceptions, are succulents but not all succulents are cacti. Although several families in addition to the Cactaceae contain succulents, the main ones are the Amaryllidaceae, Euphorbiaceae and Crassulaceae. Cacti can be distinguished from other succulents by the presence of areoles from which the barbed hairs (glochids) and/or spines arise. Other succulents that have spines do not have these special cushiony structures at the base of the spines (see Glossary, for definitions). 
To eliminate confusion in setting up classes for succulents, the show committee should make certain that the prize list clearly specifies whether only true cacti, only succulents other than true cacti, or both cacti and other succulents are to be entered.

\section{Standards of perfection}

Well-balanced growth and development, good size for the species; freedom from injury including damaged spines; if bloom is present (characteristic of some succulents) it should not be disturbed; other things being equal, a cactus exhibited with flowers is preferred to one with no flowers.

\begin{tabular}{lr}
\multicolumn{1}{c}{ Score } & \\
Condition & 40 \\
Difficulty of cultivation & 20 \\
Conformity to type (age and & \\
size) & 20 \\
Rarity & 20 \\
Total & 100
\end{tabular}

\section{FRUIT Judging standards for Alberta fruit}

A. Schernus

The first question that might arise when judging a fruit class is exactly what constitutes a fruit? Botanically, a fruit is an expanded ovary which certainly includes apples and strawberries but also includes squash, tomatoes and beans. Obviously some different definition is required. For trade purposes, Canada Agriculture considers a fruit to be 'any produce item typically consumed as a dessert course,' whereas a vegetable is 'any produce item typically consumed with the main course.' This definition also leaves considerable ground for uncertainty, as a muskmelon could be part of your main course salad or be used by itself for dessert. This confusion could be eliminated if we insist that fruit must come from a perennial plant, capable of overwintering. Considering that certain strawberries can be handled as annuals, even this definition has limitations. By these definitions we find that rhubarb logically belongs in the fruit as opposed to the vegetable section. With no definite boundaries, the above definitions combined with common sense and traditional usage are possibly the judge's best guides as to what constitutes a fruit.

Since fruit has typically not occupied a large portion of Alberta home gardens and landscapes, it is rarely the central focus of a show. As a result, the timing of many shows is aimed more at the flower and vegetable classes with the result that the show is often too early for much of the fruit crop to be shown to best advantage. This is a reality that judges must recognize and make allowances for.

In order to force a level of uniformity among specimens in an exhibit as well as to create a larger visual impact, multiple specimens in an exhibit are required. The number varies with the specific fruit as is outlined below. Exhibitors entering more than the required number would not normally be disqualified but no positive considerations would be given to the larger number. An exhibit containing less than the required number may be considered if there were very few entries in the class but the entry would be severely discounted. In a large class, an entry with insufficient numbers would most likely be disqualified.

Recommended Numbers Constituting an Entry

Apples (under $5 \mathrm{~cm}$ diameter) $\ldots \ldots \ldots \ldots \ldots \ldots \ldots$

Apples (over $5 \mathrm{~cm}$ diameter) $\ldots \ldots \ldots \ldots \ldots \ldots \ldots$

Apricots ................................. 10

Cherries (e.g. Nanking, Mongolian, etc.) . . . . . . 20

Currants (black or Missouri) _............ 20

Currants (red or white) $\ldots \ldots \ldots \ldots \ldots \ldots \ldots$. clusters

Gooseberries ................... 20 


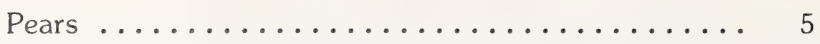

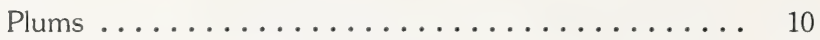

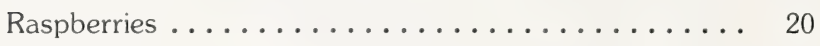

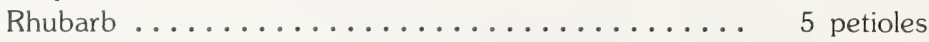

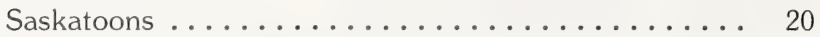

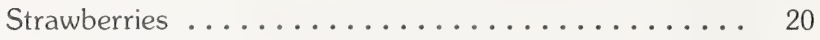

Fruit not listed $\ldots \ldots \ldots \ldots \ldots \ldots$ (any number in multiples of 5 [e.g. large fruit 5 , small fruit 10,15 or 20$]$ ).

Depending on local practice, show committees may wish to create specific fruit classes other than those listed. Every show, however, should have a "Fruit Not Listed" class so as to enable gardeners with some unusual item to display their produce to educate the public.

\section{Judging Standards for Fruit in Alberta}

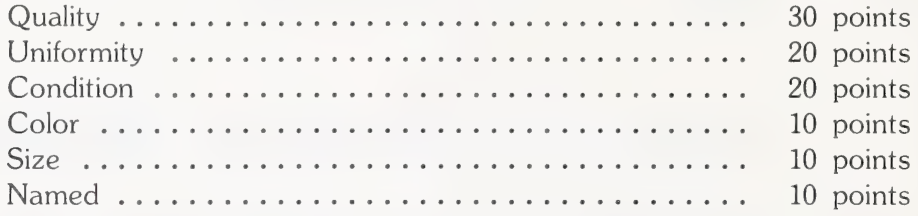

\section{Definitions}

Quality - A particular and essential character, quality is an inherent feature. In general, some quality considerations with fruit would be appropriate texture, absence of fibre, presence of sugars, flavor and aroma. Quality appropriate to the fruit's most common use must be considered (e.g. dessert or fresh eating vs cooking or processing). Specific quality features will be discussed under each crop.

Uniformity - Specimens within an entry should be as much like each other as is possible in all of the above standards and all other respects. This ensures the exhibitor has a reasonable quantity of product available as it is much more difficult to display several good and uniform entries than simply one item that may be excellent.

Condition - This is a state of physical fitness or readiness for use as indicated by lack of blemish, bruising, insect damage or any other negative physical condition which the grower could have prevented.

Color-Preference is given to bright, rich and clear color that is typical of top quality fruit.

Size - Large size is preferred providing it does not negatively affect other standards. When large size does negatively impact on other standards, not only will the entry lose points on each of the other standards (e.g. quality, condition) but will also lose points for inappropriate size.

Named - Considering that one of the major objectives of a show is educational, it is highly desirable that when possible the cultivar of fruit be named. It is recognized that many home gardeners are unaware of what cultivar they have but this does not change the value of knowing, thus in a case such as this, the entry would be tagged as "cultivar unknown". If the plant has been grown from the seed of a known cultivar, it should be designated as a "seedling of". If a judge is certain that an entry is misnamed this would be grounds for disqualification as misnaming actually has a negative educational value. However, considering that climate, soil, and cultural conditions can result in wide variations in fruit, the judge should give the exhibitor the benefit of the doubt if not absolutely certain an error has been made. 


\section{APPLES}

The division between apples, crabs and apple-crab crosses is far from certain even to those with extensive experience in fruit. To alleviate the confusion that results from such classification, it is recommended that apple classes be divided on the basis of size rather than genetic makeup. A logical division may occur at about $5 \mathrm{~cm}$. Apples should be firm, crisp, with stem attached but neatly trimmed and the fruit wiped. Dessert apples should be sweet while sourness (high acid) is acceptable in cooking apples.

\section{APRICOTS}

They should be fully ripe with a clear, unwiped skin. Flesh should not be excessively soft but flavorful and sweet.

\section{CHERRIES}

(Nanking, Mongolian, Sandcherries) - They should be full ripe, soft but not bleeding (leaking juice), shown wiped with stems removed. Preference is given to sweet, flavorful fruit.

\section{CURRANTS}

(Black or Missouri) - There are many species of currants with varying common names resulting in considerable confusion as to correct division of classes. To aid in separation, the following should be helpful. Black currants tend to be smaller, with a somewhat bitter aroma and taste. Missouris tend to be larger with a sweet aroma and taste. In addition, Missouri may also come in amber or red colors but will not be confused with ordinary whites and reds because of the Missouri's larger size and habit of being borne as individual berries rather than in clusters. Further, red or amber and immature black Missouris have a bit of a stripe on the fruit somewhat similar to gooseberries. In all cases, fruit should be shown with stems intact but the calyx (blossom end) removed. Fruit should be large, ripe, plump, and bright.

\section{CURRANTS}

(Red or White) - Currants may be shown in the same or separate classes but in any case will be shown in compact clusters containing large numbers of large ripe, bright, and uniform fruit. Skins should be intact with no sign of bleeding.

\section{GOOSEBERRIES}

They may be either green or ripe but in either case the entry should have a uniform stage of maturity. When comparing entries some preference will be given to a ripe exhibit with full and sweet flavor. Stems should be left on but with calyxes removed. Especially watch for maggot damage. 


\section{PEARS}

Fruit should be neither excessively soft nor gritty, stem should be intact but neatly trimmed and fruit should be wiped. Flavor should be full and sweet.

\section{PLUMS}

Fruit and flesh color may vary considerably but in all cases should be clear. Fruit should be soft yet not mushy and flesh should be sweet. Bloom (natural waxy coating) should be intact and not smudged. Stems are left intact.

\section{RASPBERRIES}

Bright colors are preferred to dark which may be a sign of overmaturity. Stems and calyx are left intact, fruit is ripe yet not excessively soft. There will be no sign of bleeding and flavor will be full and sweet.

\section{RHUBARB}

Long and large diameter petioles are preferred provided this size does not adversely affect quality. Quality considerations are relative freedom from fibre as indicated by snapping, and a sweet, relatively nonacid taste. Red color, exterior and interior, is preferred to green. Leaf should be trimmed to a fan shape $2.5 \mathrm{~cm}$ from the petiole. The petiole is harvested by pulling rather than cutting with only the loose tissue at the base trimmed away.

\section{SASKATOONS}

Berries should be full ripe and darkly colored, not shrivelled and should have stems removed. Skin should not be tough and flesh should be juicy and relatively free of seeds. Flavor should be full and sweet.

\section{STRAWBERRIES}

Stem and calyx are left intact. Berries will be without catfacing (deep creases) or hard noses. Bright rather than dark red is preferred on both exterior and interior. Core should be small and inconspicuous. Fruit should be full ripe yet not mushy or bleeding. Flavor should be full and sweet.

\section{FRUIT NOT LISTED}

In this class, the judge may indeed be comparing apples and oranges. Thus each fruit stands on its own merits as opposed to being compared to another. Quality standards for any of the many other fruits cannot be specified, however, the judge must keep in mind the purpose for which the fruit would normally be used. For jellies or jams, a high acid and pectin content are desirable while sugar is not as important. Wine requires a high sugar content and full flavor. Fresh eating requires good texture with full flavor, sweetness and aroma. Common sense will be the judge's best friend in this class. 


\section{Fruit preserves}

Considering that many fruits are either overmature or not yet ready by showtime, this has resulted in the fruit class being rather small in most shows. To encourage exhibitors and to educate the public, show committees may wish to give consideration to a fruit preserves class. Typically entries should be from the previous season's crop. Entries must be in clear glass jars, usually of a specified size.

Judging is done on the basis of appearance alone by the following standards:

Condition of fruit $\ldots \ldots \ldots \ldots \ldots \ldots \ldots \ldots \ldots$ points

Color ..................... 20 points

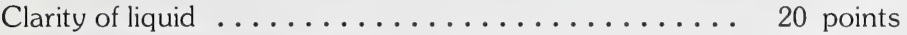

Fullness and neatness of pack $\ldots \ldots \ldots \ldots \ldots \ldots \ldots$ points

General attractiveness ................ 10 points

Labelling ..................... 10 points

\section{Fruit collections}

This class gives exhibitors the opportunity to display the wide range of fruit from their garden. Usually a minimum number will be specified such as eight different and distinct kinds of fruit (e.g. yellow and red raspberries would only qualify as one kind). The number of specimens of each kind should also be specified. If in doubt as to the number of each kind it should equal the number required if the fruit were to be shown in a class of its own. No accessories (flowers, etc.) should be used in a collection. Collections may also include a specified number of activities of a single kind of fruit (e.g., eight cultivars of apples).

\section{Fruit displays}

This class allows exhibitors to not only show the diversity of fruit from their garden but also allows an artistic presentation of it. Usually a certain minimum number of kinds will be specified as will a certain maximum area the arrangement may cover. Accessories such as flowers, branches, leaves, and containers, are allowed and are an important but not dominant part of the display.

\section{Judging standards for collections and displays}

Diversity (kinds, types and cultivars) Collections Arrangement and design 
The standards of perfection, particularly where preferences are expressed, are based on consumer surveys as shown in the market place.

The three following criteria are considered most important:

\section{Quality}

This important standard will be discussed in detail for each vegetable.

\section{Condition}

Condition of vegetables refers to their freshness and freedom from blemishes caused by insects, diseases, soil and mechanical damage. The degree of freedom should be stated in the prize list, for example, "free" or "reasonably free". In dealing with biological specimens we prefer "reasonably free".

\section{Uniformity}

Specimens should be as uniform as possible in color, maturity, shape and size. This standard adds considerably to competitiveness in a show. It is more difficult for an exhibitor to exhibit several uniform specimens than a single specimen.

Standards of lesser importance which may be used are:

\section{Size}

Size should be moderate, not large; that is, the size in which all the other qualities of the cultivar are found to their greatest perfection.

\section{Trueness to type}

All specimens are required to be as true to type specified as it is possible to grow and select them. Example:

$\begin{array}{lll}\text { Kind } & \text { Type } & \text { Cultivar (variety) } \\ \text { Beans } & \text { green } & \text { Bush Blue Lake } \\ & \text { wax } & \text { Midas } \\ \text { Cabbage } & \text { green } & \text { Golden Acre } \\ & \text { red } & \text { Meteor } \\ & \text { savoy } & \text { Baby Savoy }\end{array}$

\section{Color}

The color should be bright, clear and attractive. Color in vegetables is largely a cultivar characteristic and uniformity of color is a good index of proper culture and handling of vegetables. Usually a dark or rich color is preferred.

\section{Classes}

Specimen classes (kinds of vegetables)

Suggested quantities for best display.

$\begin{array}{ll}\text { Vegetable (kind) } & \text { Plate of } \\ \text { Beans } & 12 \text { pods } \\ \text { Beets } & 5 \text { roots } \\ \text { Broccoli } & 2 \text { heads } \\ \text { Brussels sprouts } & 2 \text { stalks and } 12 \text { sprouts } \\ \text { Cabbage } & 2 \text { heads } \\ \text { Carrots } & 5 \text { roots } \\ \text { Cauliflower } & 2 \text { heads } \\ \text { Celery } & 2 \text { heads } \\ \text { Chard, swiss } & 2 \text { plants } \\ \text { Citron } & 2 \text { fruits } \\ \text { Corn, sweet } & 2 \text { ears } \\ \text { Cucumbers (slicing) } & 2 \text { fruits } \\ \text { Cucumbers (gherkins or pickling) } & 6 \text { fruits } \\ \text { Eggplant } & 2 \text { fruits } \\ \text { Garden herbs } & 5 \text { or more species }\end{array}$


Kale

Kohlrabi

Leeks

Lettuce

Muskmelon (cantaloupe)

Onions (cooking)

Onions (pickling)

Onions (green bunching)

Parsnips

Peas

Peppers

Potatoes

Pumpkin

Radishes

Rhubarb

Spinach

Squash

Tomatoes (red or green)

Tomatoes (pickling or preserving)

Turnips

Watermelon
2 plants

2 stems (plants)

2 plants

2 heads

2 fruits

5 bulbs

12 bulbs

12 plants

5 roots

12 pods

5 fruits

5 tubers

2 fruits

5 roots (plants)

5 stalks

2 plants

2 fruits

5 fruits

12 fruits

2 roots

2 fruits

\section{Collections}

This is a group of a number of kinds of vegetables in one exhibit. More than one type of one kind constitutes only one kind of vegetable. Upper and lower limits of numbers, and also the area to be occupied, should be specified. Other factors being equal, an exhibit containing kinds (or cultivars) that are rare or difficult to grow should be given preference over an exhibit containing easily grown specimens. Herbs should be considered a vegetable in a collection. All vegetables should conform to requirements given for specimen classes (refer to "Standards of perfection" section for details).

\section{Score}

Quality and condition 30

Number of kinds (or cultivars)
Arrangement and attractiveness

25

Shape, size and color of specimens

Educational value (correct and suitable labeling)

Total 
In a display of vegetables, the attractiveness of the arrangement and its general effect are given more emphasis than in a collection. Use of other living plant material for decorative purposes is allowed. Herbs used in a display only for decorative purposes should not be counted as a vegetable. All vegetables should conform to requirements given for specimen classes (refer to "Standards of perfection" section for details).

\section{Score \\ Arrangement and attractiveness 40 \\ Quality and condition 35 \\ Number of kinds (or cultivars) 15 \\ Educational value (correct and suitable labeling) \\ Total

\section{Standards of perfection}

The standards of perfection, particularly where preferences are expressed, are based upon consumer surveys as shown in the market place.

\section{BEANS}

Wax and green should be in separate classes. Pods should be uniform, of good length, of color typical for the cultivar, clean and free from blemishes. Edibility is important, and pods should be crisp, fresh, fleshy, and free from stringiness and fibre. Stem and calyx should be attached. Lumpy pods are undesirable and generally indicate seed development has occurred. Long, straight pods are preferred over pods which have a curved shape or are flat. Purple beans should be exhibited in the novelty class.

Score - Quality 25; Uniformity 25; Condition 20; Color 15; Type 15.

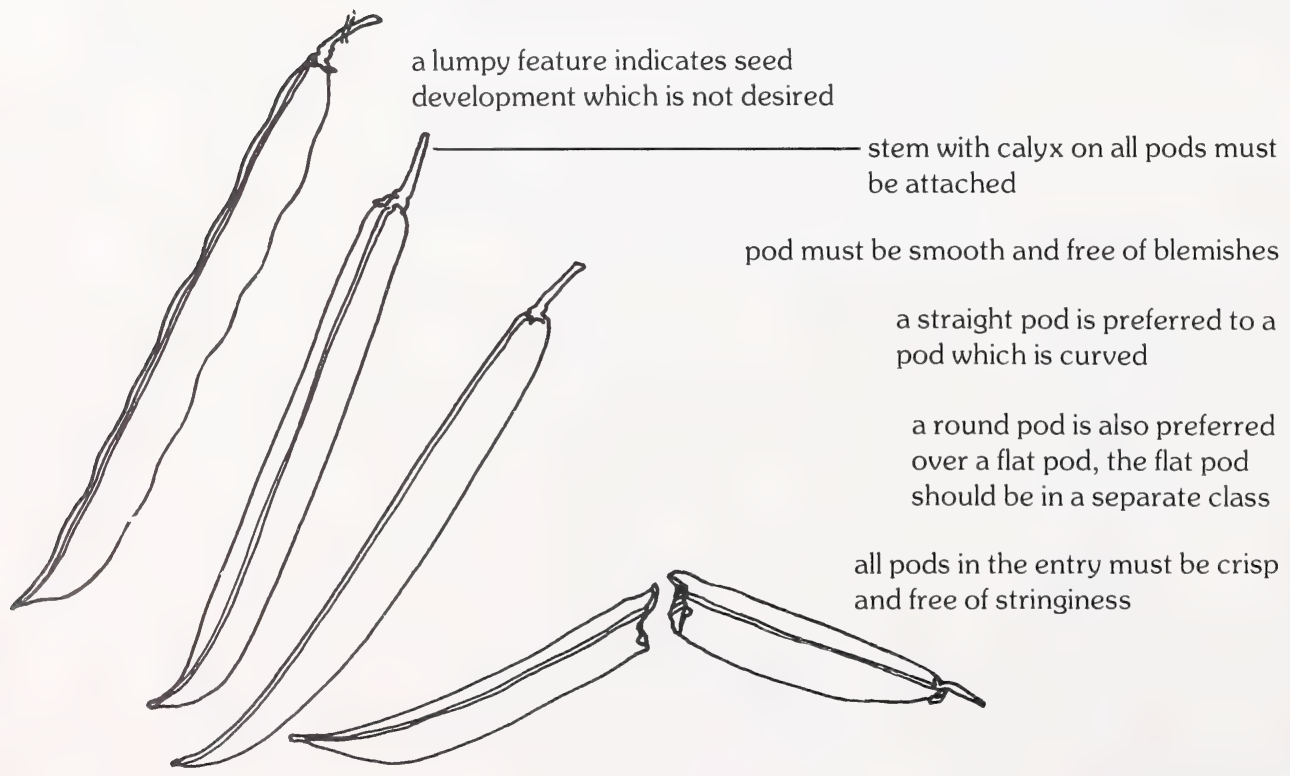




\section{BROAD BEANS}

Pods should be large, fresh, well filled with thin skins and tender seeds. Each pod should have all seeds present with no aborted ovules. Cultivars with green seeds are preferred. (Not to be confused with scarlet runner beans.)

Score - Quality 30; Condition 30; Uniformity 25; Size 15.

\section{BEETS}

Long or cylindrical - Diameter at top 3 to $5 \mathrm{~cm}$ (1.5 to $2 \mathrm{in}$.). Roots trimmed to reasonable length; color dark red. Crown or beet should be free from splits, scaling, scabs and sunburn; inside of beet free from white growth rings (zones). Tops should be removed $1 \mathrm{~cm}(0.5 \mathrm{in}$.) above the crown.

Globe or round-Diameter 5 to $7 \mathrm{~cm}$ (2 to 3 in.); otherwise, same as for long cultivars. Many colors are also available, however the red is preferred over yellow or white cultivars.

Score - Color (exterior 10, interior 15); Uniformity 25; Condition 20; Quality 20; Type 10.

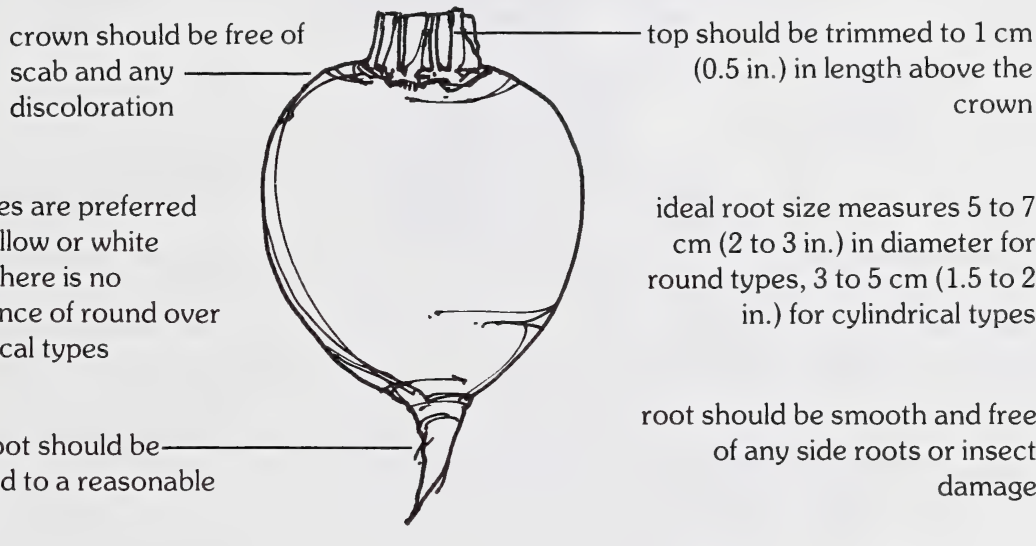

cylindrical types main root should bemain root should belength

red types are preferred over yellow or white beets, there is no preference of round over root should be smooth and free of any side roots or insect damage

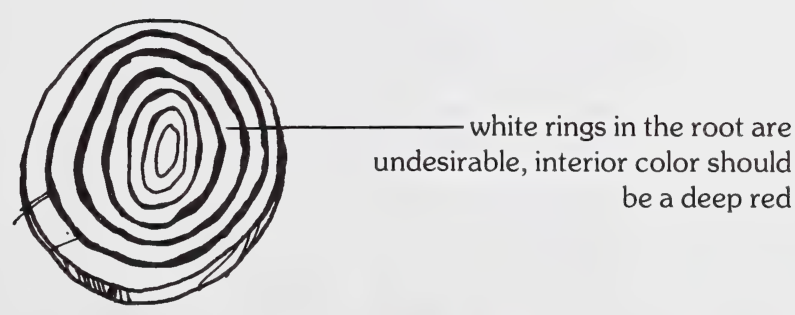

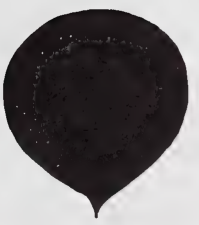

round or globe

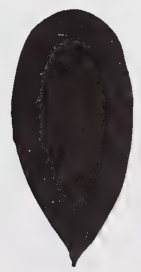

cylindrical 


\section{BROCCOLI}

Head formation should be dense and uniform, smooth, not faded in color which when ideal should be blueish-green, or overmature where florets show yellow color. Stem should be at least $10 \mathrm{~cm}$ long and branch high near the head. No crack should appear in cut end of stem. Purple broccoli should be in a separate class on its own or in the novelty class.

Score - Color 20; Condition 20; Quality 20; Uniformity 20; Size 10; Type 10.

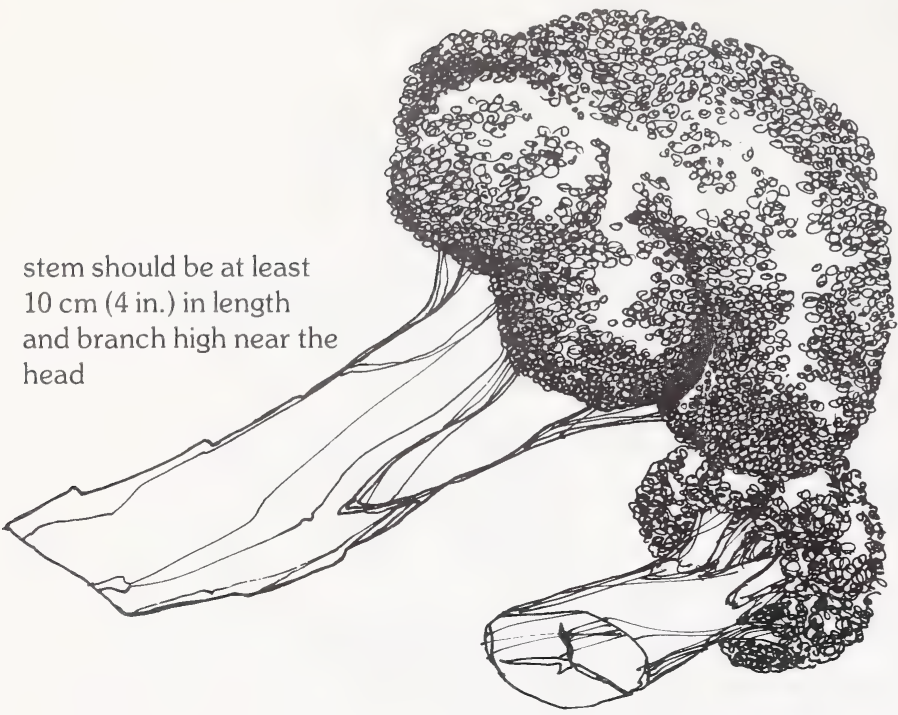

a stem with no crack is preferred a yellowish color near centre of head is called "yellow eye", florets in such cases are usually poorly developed

head should be large and show dense, uniform development of all florets, a bluish-green color tinge is desired

the larger head is preferred provided quality is good

no leaves should br growing in the head

lower sideshots should be trimmed neatly

check inside the head for insects and insecticide residues

\section{BRUSSELS SPROUTS}

Stalks should be exhibited with only a few of the top leaves left on but with the root removed. Sprouts must be numerous, of uniform size, firm, closely set, making as heavy a stalk as possible; and must be free from aphids and other pests. Individual sprouts, 12 per plate, may also be exhibited.

Score - Quality 30; Uniformity 25; Condition 20; Color 15; Type 10.

\section{CABBAGE}

Green, red, and savoy - All types should be exhibited in separate classses. Heads should be uniform, firm and of moderate size, 12 to $20 \mathrm{~cm}$ (5 to $8 \mathrm{in}$.) in diameter. They should be free from pest injury and other blemishes, with stem trimmed to a butt and with one or two wrapper leaves retained. Savoys should be as well matured as possible. The crumple should be fine. The same amount of firmness is not expected in savoys as in ordinary types of cabbage. Red cabbage should comply with the general requirements of the green cultivars, but should be as dark red as possible. All types when cut should have a short core with thin leaf bases which are closely spaced.

Green types are most preferred followed by red and then savoy. Round types are also preferred over flat and pointed types.

Score-Quality 35; Condition 20; Uniformity 20; Color 15; Type 10. 
green types are most preferred by the market followed by red and then savoy, all three types should be shown in separate classes

the market prefers a round head which is 12 to $20 \mathrm{~cm}$ (5 to $8 \mathrm{in}$.) in diameter

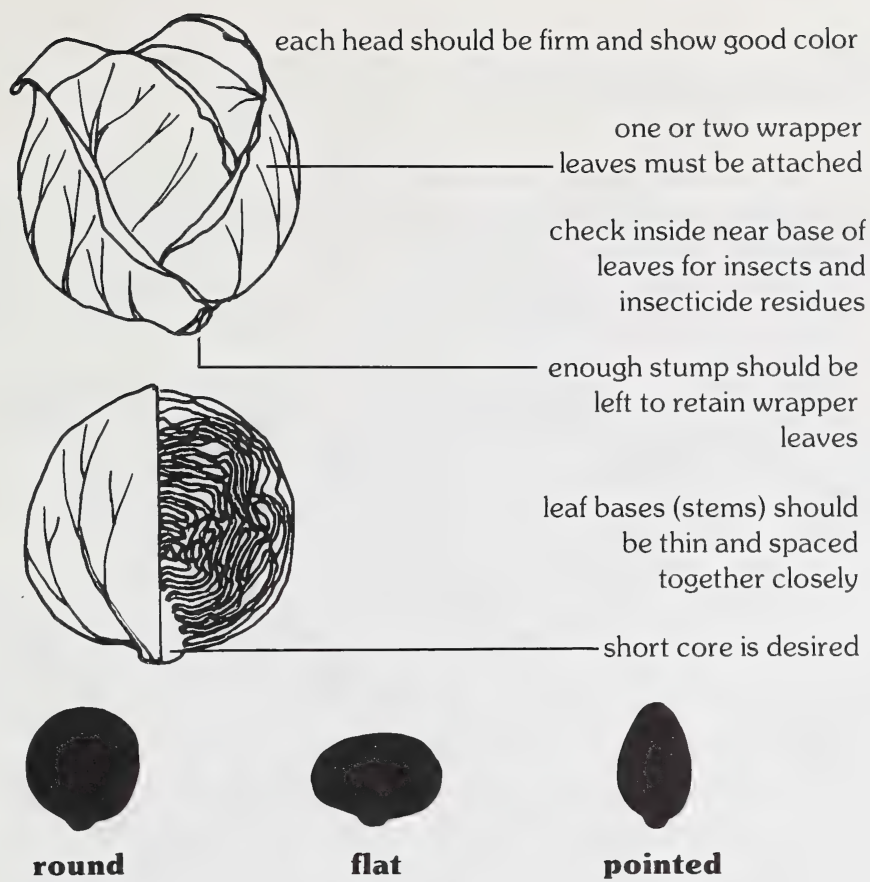

\section{CARROTS}

Long - Length $17 \mathrm{~cm}$ (7 in.) or over. Carrots should be uniform, slender and distinctly pointed with roots trimmed to a reasonable length, free from sunburn, discoloration, side roots, and pest and mechanical injuries. The core should be as small or inconspicuous as possible and flesh should be tender, sweet, and of bright color. Lenticels should be shallow and free of soil. Tops should be removed $1 \mathrm{~cm}$ above the crown. Chantenay types with broad shoulders are undesirable and should not be exhibited.

Intermediate - Length not over $17 \mathrm{~cm}$ (7 in.). Carrots should be stump-rooted. Other qualifications as for long class. This type of carrot is most preferred.

Short - Length not over $7 \mathrm{~cm}$ (3 in.). Carrots distinctly stump-rooted. Other qualifications as for long class.

Score - Color 25; Uniformity 25; Condition 20; Quality 20; Type 10.

crown must be free of any greening

tops must be trimmed to $1 \mathrm{~cm}-$

( $0.5 \mathrm{in}$.) in length above the

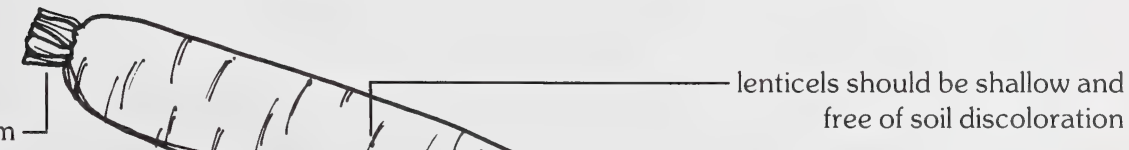
crown

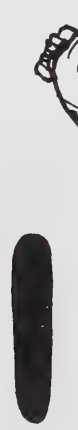

Nantes

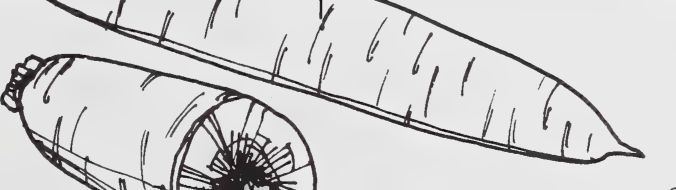

core must be small and exhibit a deep orange color
Nantes types are preferred, Chantenay less so; Nantes are preferred because of the small core and superior eating quality 


\section{CAULIFLOWER}

Heads should be 12 to $20 \mathrm{~cm}$ (5 to 8 in.) in diameter, uniform in size, color, and preparation; compact, smooth and regular in form, with good depth of curd; pure white in color, with no green leaves showing through. Stalk and larger leaves should be removed; those leaves remaining should be trimmed off $1 \mathrm{~cm}(0.5 \mathrm{in}$.) above the level of the head.

Score - Color 20; Condition 20; Uniformity 20; Quality 20; Size 10; Type 10.

stems and leaves must be trimmed in a straight line which measures 1 $\mathrm{cm}(0.5$ in.) above height of the curd

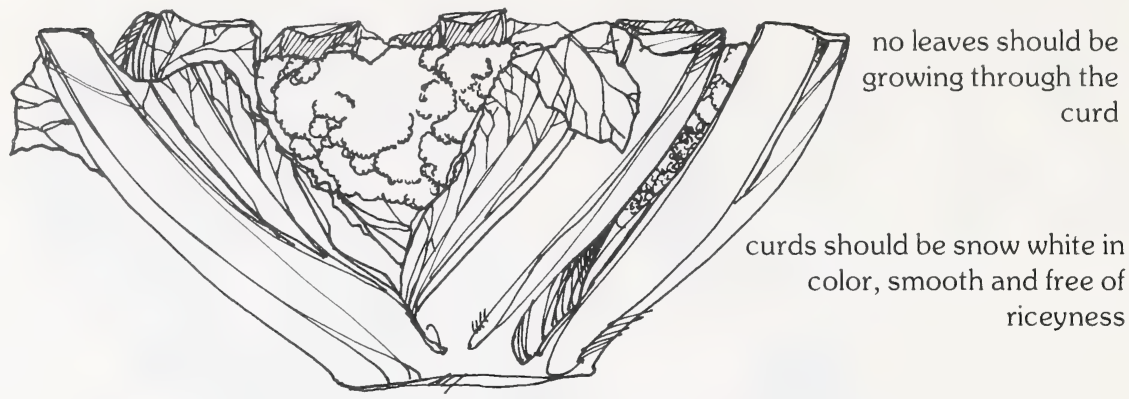

ideal head size is 12 to $15 \mathrm{~cm}$ (5 to 6 in.)

in diameter across the top of the curd

\section{CELERY}

Entries should be uniform in size, length of stalk, and color. They should be free from disease and blemishes. Most cultivars should be as large as possible, consistent with good condition and firmness of stalk. Color is important and should be true to type for the cultivar. Color must be clean and uniform. In form, the bunch should be long and stout, solid and heavy, with stalks closely set and as many as possible of full length. The rootstock should be trimmed down to a conical point and the small and broken outer stalks (petioles) removed. All suckers should also be carefully removed. Quality is most important and is determined by a test of average stalks, which must be firm, brittle, and free from pithiness and stringiness.

Score - Quality 30; Uniformity 25; Condition 25; Color 10; Type 10.

all suckers (plantlets) should be carefully removed

crown should be large, leaf bases should be broad and free of cracking

blackheart, a slimy decay in the heart should not be evident

celery should be clean and crisp

stalks should be long, broad and free of stringiness 


\section{SWISS CHARD}

Root should be trimmed to a conical point and the plants exhibited in a manner similar to celery. Leaves and petioles should be large, broad and tender.

Score - Quality 35; Uniformity 20; Condition 20; Color 15; Type 10.

\section{CITRON}

Entries should be fair sized, uniformly round, well mottled, of good weight, firm and free from sunburn and bleached patches. Stem must be attached to fruit.

Score - Quality 35; Condition 20; Uniformity 20; Size 15; Type 10.

\section{SWEET CORN}

Only sweet, fresh garden corn should be exhibited in this class and all cultivars should be named. Ears should be uniform in size and form, evenly filled from tip to base, with rows of kernels long, straight and closely set. At ideal maturity the kernels should have milky texture. The husked ears should be of fair size, free from blemishes, of clear and bright color, and uniform according to cultivar. The stalk should be cut smooth at butt end of cob. Ears should be shown with a third of the husk removed.

Yellow kernel corn is preferred to bicolor and white types, however white types are more difficult to grow and should be given consideration.

Score - Quality 35; Uniformity 25; Condition 15; Color 15; Size 10.

one-third of the husk must be removed, silk should be removed or carefully groomed

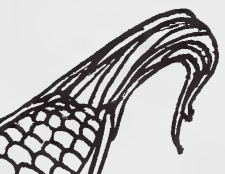

a milky kernel indicates ideal stage of maturity

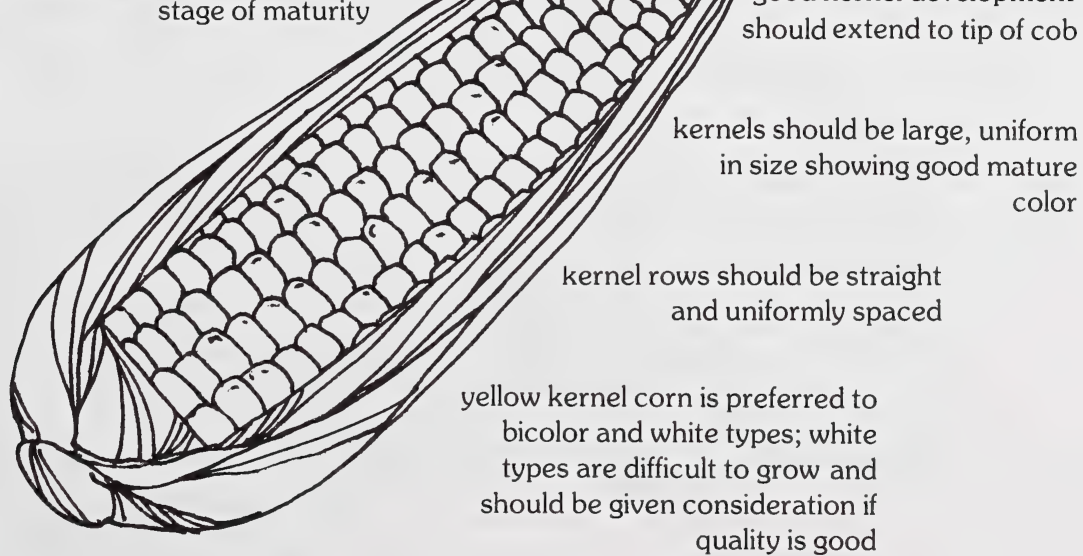

stalk should be cut smooth 


\section{CUCUMBERS}

Slicing - Slicing cucumbers are of two distinct types and should be entered in separate classes; standard (American) and long English (European). Both types should have stems attached, $1 \mathrm{~cm}$ ( $0.5 \mathrm{in}$.) in length, be unblemished with no yellow underside (yellow belly), uniform in size and not showing very much taper from stem to blossom end. American type should have a minimum number of seeds and be at least $15 \mathrm{~cm}(6 \mathrm{in}$.) in length. European types should not have seeds and be at least $25 \mathrm{~cm}$ (10 in.) in length.

Pickling - Pickling cucumbers should be uniform, of good green color, on an average of 5 to $7 \mathrm{~cm}$ ( 2 to $3 \mathrm{in}$.) long, not showing very much taper from stem to blossom end. They should be clean and without the withered blossom. Spines should be left intact and be black in color. Stems $1 \mathrm{~cm}(0.5 \mathrm{in}$.) in length must be attached.

Score - Quality 25; Condition 20; Uniformity 20; Color 15; Type 10; Size 10.

all fruit should be of uniform shape from stem end to blossom end with no tapering toward blossom end
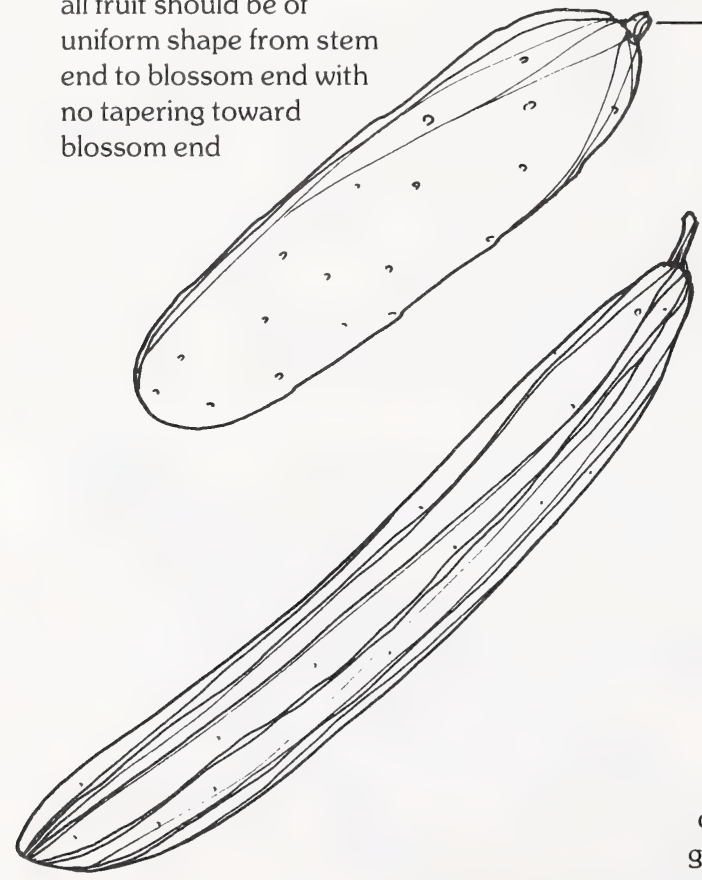

stems must be attached to all fruit

fruit should be uniform in color with no yellow underside (yellow belly) evident

spines should be left intact on all types that bear spines

slicing cucmbers should be a least $15 \mathrm{~cm}$ (6 in.) long, pickling cucumbers should be 5 to $10 \mathrm{~cm}$ (2 to 4 in.) long, European types should be at least $25 \mathrm{~cm}$ (10 in.) in length

check for bitterness which is generally concentrated at the stem end of pickling types
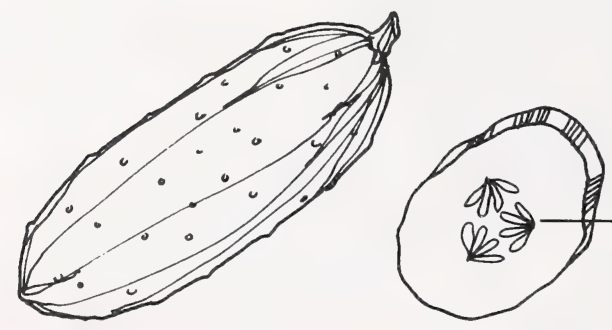

seed should be small and immature in development, no bitter taste of fruit should be detectable 


\section{EGGPLANT}

Specimens should be of good size, uniform, firm, even in color, and free from blemishes and bronzing. Stem, $1 \mathrm{~cm}$ ( $0.5 \mathrm{in}$.) in length, must be attached. They may be wiped, but should not be washed or oiled. Eggplant is considered difficult to grow, particulary those cultivars with egg-shaped fruit.

Score - Quality 30; Condition 20; Uniformity 20; Color 20; Type 10.

\section{GARDEN HERBS}

Collections of fresh herbs, preferably in containers, should contain five or more species, such as savory, mint, sage, thyme, sweet marjoram and chives. An attractive bunch of each should be prepared, free from blemishes and diseased portions, and embodying healthiness and vigor of growth for the season. For the benefit of the general public all bunches should be labeled plainly and neatly.

Score - Condition 35; Quality 25; Uniformity 20; Color 20.

\section{KALE}

The plants should be uniform in all respects, and vigorous, clean, heavy, with large, dark, numerous well-curved leaves. Roots should be removed.

Score - Condition 35; Quality 25, Uniformity 20; Color 20.

\section{KOHLRABI}

Specimens should be well matched in size 4 to $6 \mathrm{~cm}$ ( 1.5 to $2.5 \mathrm{in}$.) in diameter with flesh that is crisp, tender, solid, free from cracks and sweet in flavor. The roots should be trimmed to $1 \mathrm{~cm}(0.5 \mathrm{in}$.) just below the ball or swelling and four to six of the centre leaves should be allowed to remain. Both purple and green types are equally desirable. Purple require a slight longer growing period.

Score - Quality 25; Condition 20; Uniformity 20; Size 15; Color 10; Type 10.

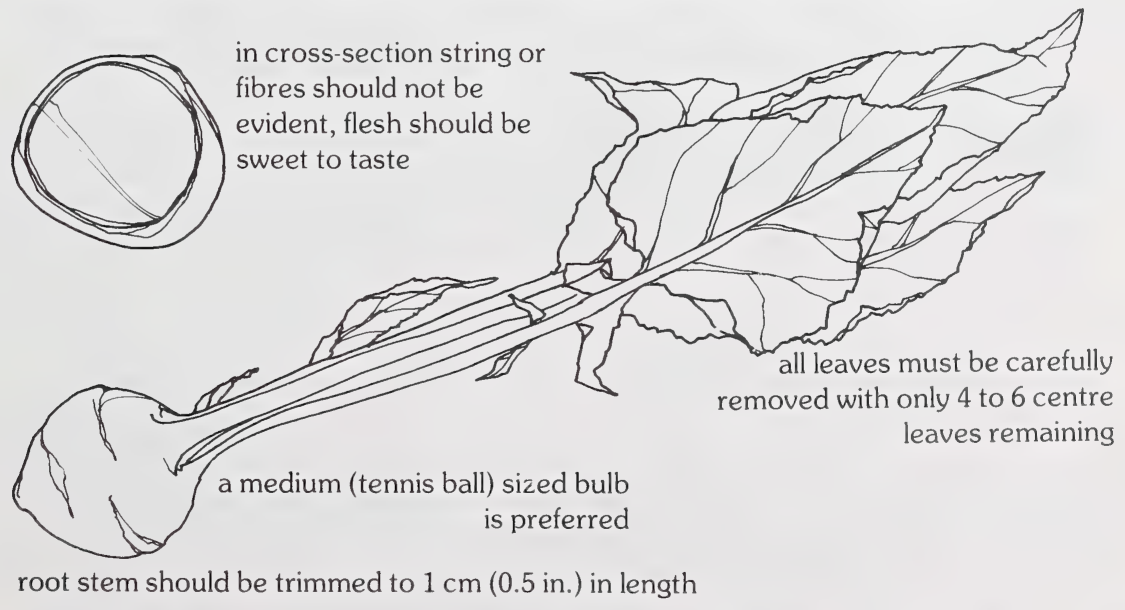




\section{LEEKS}

The stems should be long, solid, uniform, thick, well blanched, with roots trimmed to 1 $\mathrm{cm}(0.5 \mathrm{in}$.) and tops trimmed to 10 to $12 \mathrm{~cm}$ (4 to $5 \mathrm{in}$.) in length. A rounded stem tip free of bulbing is preferred.

Score - Quality 25; Condition 20; Uniformity 20; Color 15; Size 10; Type 10.

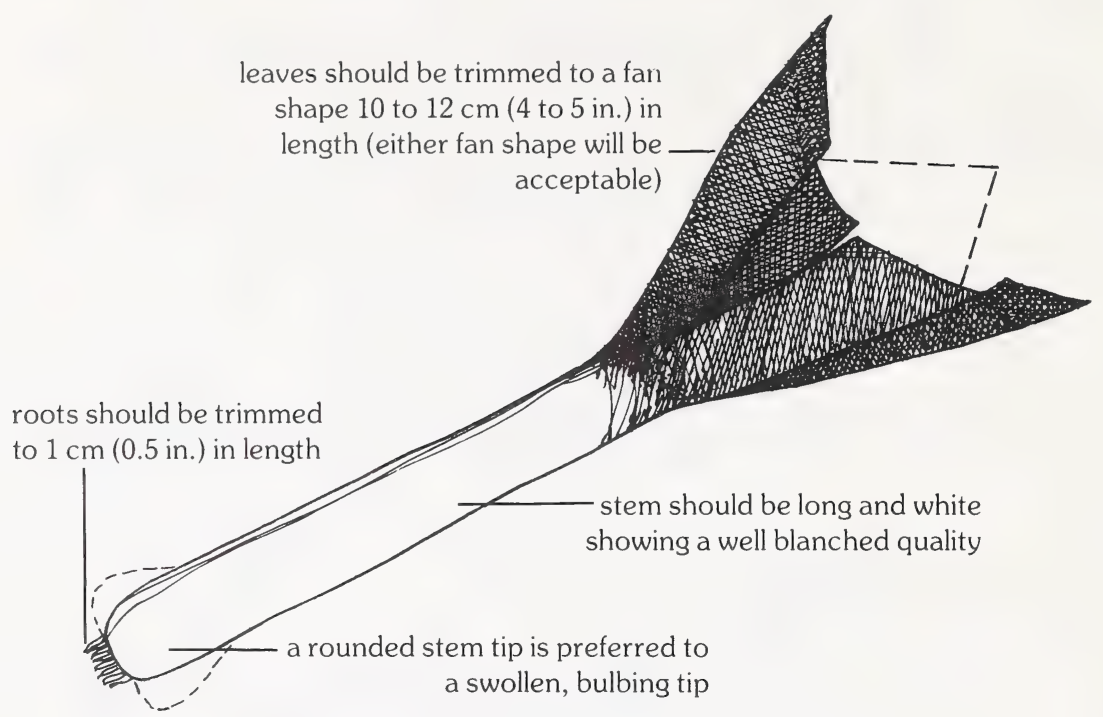

\section{LETTUCE}

The leaf, head, and Cos types of lettuce, which are commonly exhibited, should always be shown in separate classes. In large shows the head class may be subdivided into different groups e.g., crisp head (iceberg); butterhead (bibb); cos (Romaine). In all types, the heads should be large, solid, uniform, tender, sweet, of proper color, and free from pests, diseases and blemishes. The roots and only small or damaged outside leaves should be removed and the heads cleaned.

Score - Quality 30; Condition 20; Uniformity 20; Color 10; Size 10; Type 10.

\section{MUSKMELON (CANTALOUPE)}

There should be a high degree of uniformity in size and form with netting that is well developed for the cultivar. Quality is determined by removing a plug which should show thick flesh of high quality that is sweet to taste. Muskmelons are considered difficult to grow.

Score - Quality 35; Condition 20; Uniformity 15; Color 10; Size 10; Type 10.

\section{ONIONS}

Cooking (yellow, red and white) - All onions including Spanish type cultivars should be uniformly hard as well as uniform in color, size, shape and maturity. Roots and tops $(1 \mathrm{~cm}$, $0.5 \mathrm{in}$.) above the bulb should be removed. Only jagged and dirty outer scales should be removed. 
For exhibition and commercial purposes the onion bulb should be either jumbo $(8 \mathrm{~cm}, 3$ in.) in diameter or over, or standard (less than $8 \mathrm{~cm}, 3 \mathrm{in}$.) in diameter, round in shape. Oversized bulbs and bulbs flat in shape are least desired. When cut in cross-section it should show a large number of rings, as narrow as possible and closely set. No doubleeyed or thick-necked specimens should be entered.

Pickling - Round bulbed silver skins are preferred. They should be firm and well matured, not over $2 \mathrm{~cm}$ ( 1 in.) in diameter, fairly uniform, with skins clear, bright and dry. Tops and roots should be trimmed to $1 \mathrm{~cm}(0.5 \mathrm{in}$.).

Green bunching - These should be clean with loose skin removed, roots trimmed to 1 $\mathrm{cm}, 0.5 \mathrm{in}$.) in length and tops trimmed to an even length.

Score - Quality 30; Uniformity 25; Condition 20; Size 15; Type 10.

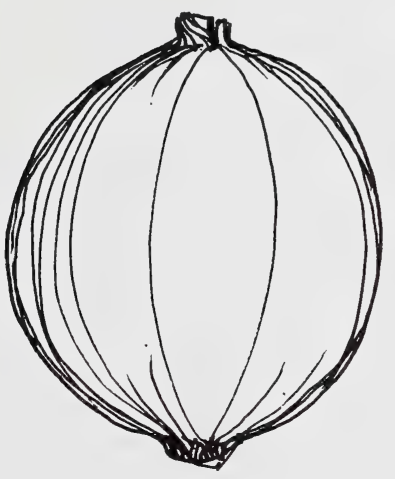

neck should be narrow and withered if bulbs are mature

tops should be trimmed to $1 \mathrm{~cm}(0.5 \mathrm{in}$.) in length, regrowth of tops is evident if immature bulbs were topped well in advance of show

outer scales should show some yellow color, excessive trimming is a common problem and is not acceptable

roots should be trimmed to $1 \mathrm{~cm}(0.5 \mathrm{in}$. $)$ in length

a cross-section should reveal a double or a singe eye (growing points), the single eye is preferred where rings are large and thick

round or globe shaped bulbs are preferred by the market, flat bulbs usually indicate origin from sets which are the easiest to grow and because of shape are least desired
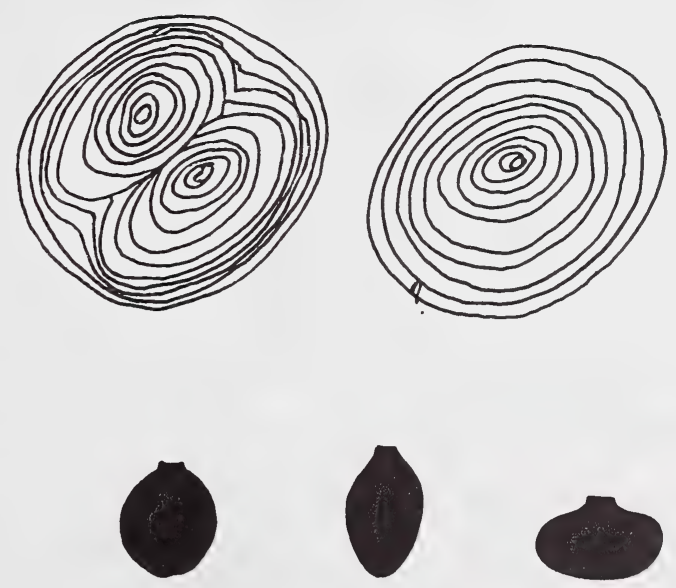

round or globe

torpedo

flat

\section{PARSNIPS}

Roots should be uniform, straight, of good length. They should taper gradually from crown to tip, be clean, firm, smooth, free from discoloration, disease and side roots, and have a small core. Tops should be removed $1 \mathrm{~cm}(0.5 \mathrm{in}$.) above the crown.

Score - Quality 30; Uniformity 25; Condition 20; Color 10; Size 10; Type 5. 


\section{PEAS}

Pods should be large, fresh, uniform, free from blemishes (flecking) and disease, and filled with large, clean, whole, uniform sized peas of a good dark green color. All pods should have a full complement of peas. Quality of peas is the most important factor. They should be sweet, full-flavored, tender and have not a grey or yellowish color. Stem and calyx should be attached to all pods.

In the class of $0.5 \mathrm{~L}$ shelled peas, the requirements are the same as for peas in pods. Exhibitors should make sure that split skins, overmature and immature peas are eliminated.

Score - Quality 30; Uniformity 25; Condition 20; Color 15; Size 10.

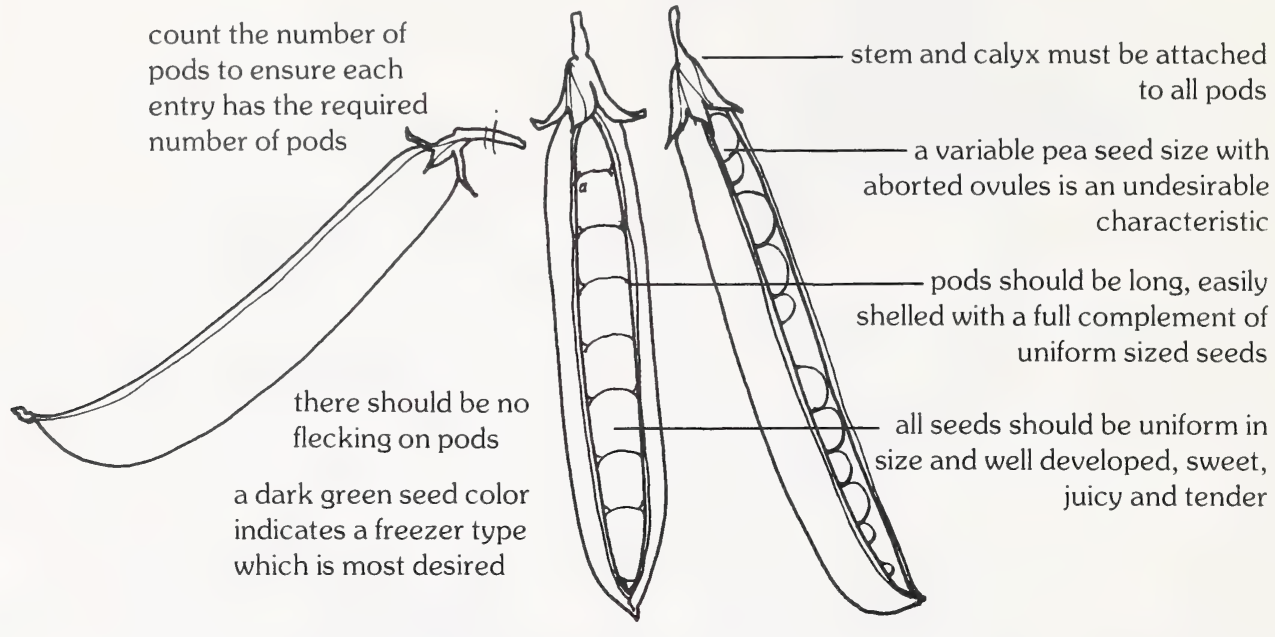

\section{PEPPERS}

The specimens should be large, uniform, firm and of good weight (with thick flesh). Stems should be left on. Bell, cherry, cayenne, jalapeno and banana types should be separate classes. Peppers are considered difficult to grow. There is a preference for the bell fruit, however, there is not preference for fruit color except for red which indicates fruit maturity.

Score - Quality 25; Uniformity 25; Color 20; Condition 20; Type 10.

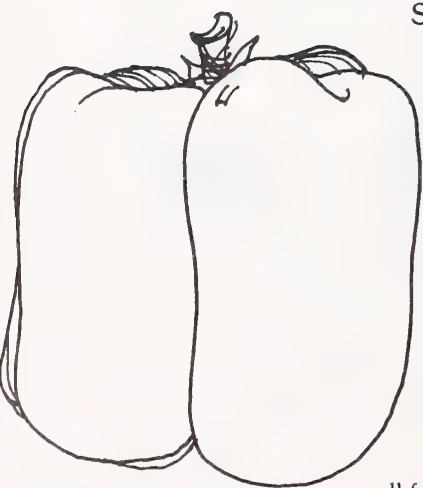
Bell (bullnose) all fruit should be firm

a $1 \mathrm{~cm}(0.5$ in.) stem must be attached to all fruits

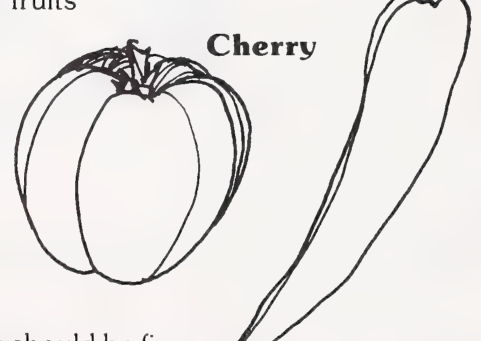
and crisp; fruit wall should be thick

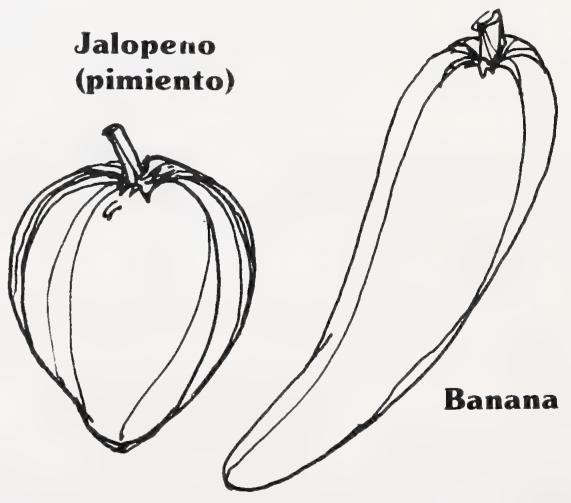




\section{POTATOES}

Trueness to type and color should be typical of the cultivar. Tubers should be clean and uniform in size; have few and shallow eyes; and be free from blemishes, especially fungus diseases such as scab, blight and rhizoctonia (black scurf). There should be neither secondary tuber growth nor any evidence of greening caused by exposure to light. Mature tubers are preferred and maturity is indicated by skin set which will not break when thumb pressure is applied. Potatoes should be clean. Separate classes for white, red and russet (netted) types are preferred.

Score - Condition 25; Quality 20; Uniformity 20; Type 15; Color 10; Size 10.

tubers should be brushed or washed clean, taking care not to break the skin all tubers should be uniformly round or oblong in shape

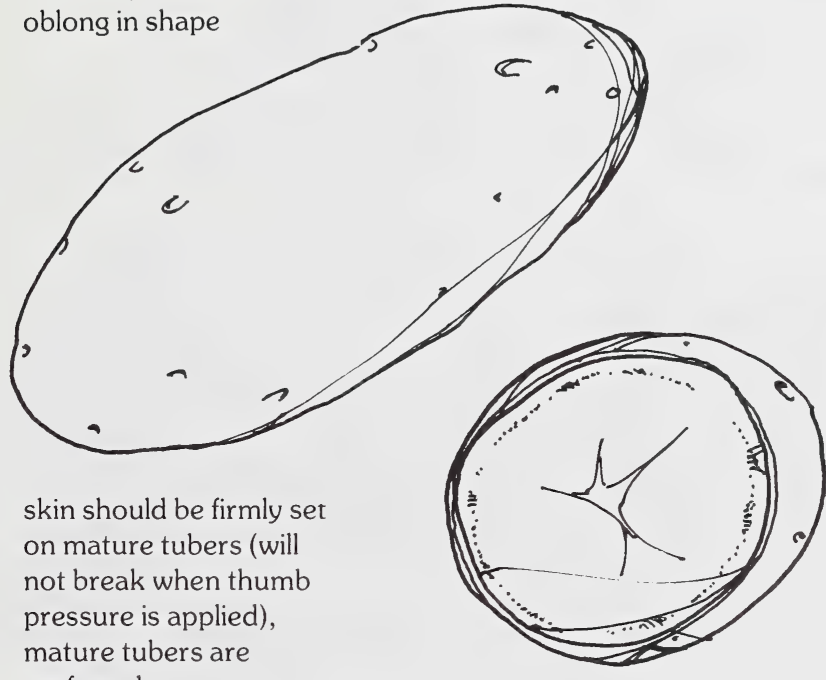

there should be no sign of scab or greening on any portion of the tubers

both hollow heart and net necrosis (virus infection) are undesirable and can be seen in cross-section

\section{PUMPKIN}

The two fruits exhibited for each entry should be uniform, especially in size and shape, of good color, free from blemishes and in good condition. They should not have any flat side and be shown with stem intact. Oblong and flat shaped fruit should be in separate classes.

Score - Quality 30; Uniformity 20; Condition 20; Color 15; Size 15.

\section{RADISHES}

These should be bunched with the tops and roots left on. Radishes should be crisp, smooth, uniform, free from blemishes, and of a clear bright color. Roots should be free of pithiness. Red rooted cultivars with round roots are most preferred.

Score - Quality 25; Uniformity 25; Condition 20; Color 20; Type 10. 


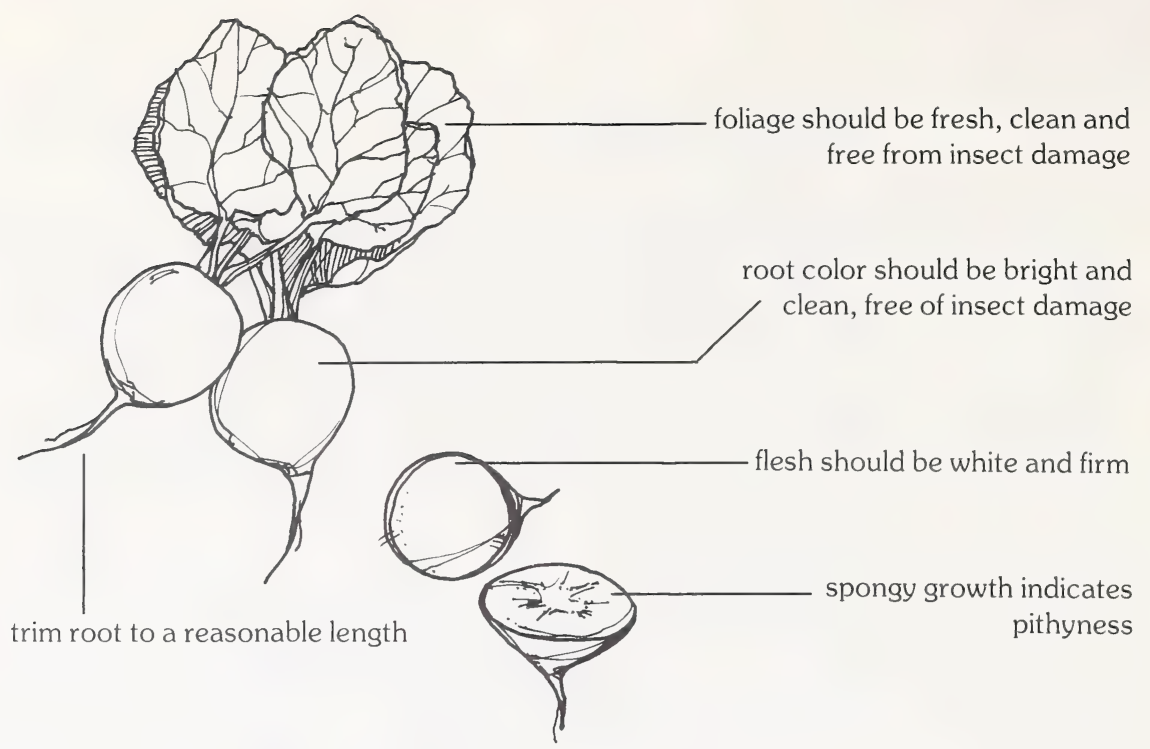

\section{RHUBARB}

The stalks should be uniform, especially in color and size - preferably at least $25 \mathrm{~cm}$ (10 in.) long and have a diameter of at least $2 \mathrm{~cm}(0.75 \mathrm{in}$.). The color should be bright red and extend over the greater part of the stalk. Stalks should be clean, smooth, plump, fresh, of good form for the cultivar. The leaf blade should be trimmed to leave about $2.5 \mathrm{~cm}$ ( 1 in.) in a fan shape. The petiole (stalk) should be left intact as pulled from the plant, except that any loose tissue at the base should be trimmed away. Quality is indicated by lack of toughness in breaking; it is desirable that stalks be as brittle and tender as possible.

Score - Quality 35; Condition 20; Uniformity 20; Color 15; Type 10.

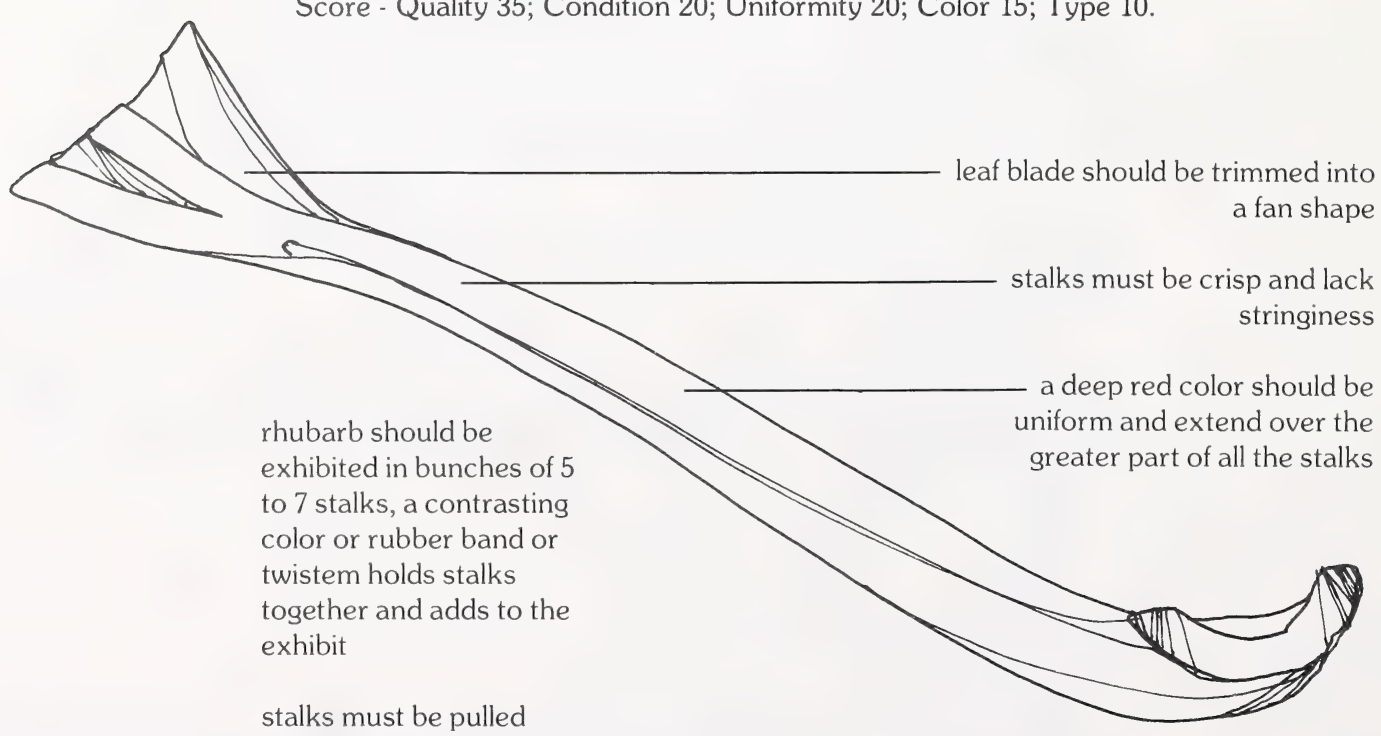

and not cut, only rough

edges should be trimmed 


\section{SQUASH}

Summer - Many colors and shapes are available. Italian types are most preferred particularly dark green cultivars. Stems, $1 \mathrm{~cm}(0.5 \mathrm{in}$.) in length, must be attached to fruit. They should be shown in pairs. Mature fruits of summer squashes should be in a separate

stems $1 \mathrm{~cm}(0.5$ in.) in length must be attached to all fruit class.

\section{Italian}

(zucchini) fruit of the Italian type should be of uniform thickness from end to end mature fruit should have skin that cannot be broken with a thumb nail

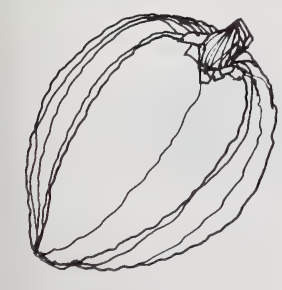

acorn

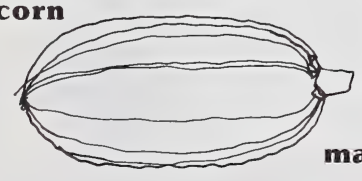

a $1 \mathrm{~cm}(0.5$ in.) stem must be attached to all fruit

Italian types are preferred and ideal size is 15 to $20 \mathrm{~cm}$ ( 6 to $8 \mathrm{in}$.) in length, young fruit with tender skin is most desirable. Overgrown, mature fruit is unsuitable and should be shown in a separate class

Italian (zucchini) and vegetable marrow - Squash should be uniform in size, color, shape, and depth of flesh. A moderate range in size for the cultivar is expected, however, fruit should be 5 to $20 \mathrm{~cm}$ in length for best quality. There should be no skin punctures or similar blemishes.

Straight-neck-Preferred next to Italian types. Requirements are the same as for Italian. Swelling at base of fruit should be moderate.

Crookneck - Fruit should be about 10 to $15 \mathrm{~cm}$ (4 to 6 in.) long, of a golden color, and moderately crooked. Swelling at base of fruit should be moderate.

Scalloped or patty pan-Specimens should be about $10 \mathrm{~cm}$ (4 in.) in diameter, uniform and of clear color. Fruits are truest to type when the scallops are deep.

Mature Italian and vegetable marrow - Fruit should be 30 to $50 \mathrm{~cm}$ (12 to 20 in.) long (smaller for table use, larger for jam), uniform, cylindrical, smooth, firm, slightly ribbed, in good condition for the season, free from all blemishes and with a $1 \mathrm{~cm}(0.5 \mathrm{in}$.) stem attached. The skin should be firm. This includes both the green and cream varieties. This type is often classified as winter squash.

Winter - The acorn, followed by the buttercup and hubbard are the principal longkeeping winter squash and are preferred in that order. They are shown in pairs, with $1 \mathrm{~cm}$ (0.5 in.) stems attached, and should be uniform in size, form and color, as well as free from blemishes. Warted hubbard cultivars should be evenly well warted and should be 25 to 30 $\mathrm{cm}$ (10 to 12 in.) in diameter. Colors of all types should be typical of the cultivar with a minimum of white (yellow-belly) on the under side. Mature fruit is preferred in which the skin cannot be broken by the thumb nail.

Score - Quality 30; Uniformity 20; Condition 20; Color 15; Size 15.

acorn fruit is preferred, followed by buttercup, marrow then hubbard; there is no external fruit color preference 


\section{TOMATOES}

Fresh, large or cherry fruit should be in separate classes. Green and red fruit should also be in separate classes. All fruit should be smooth, uniform in size, shape and color, and free from blemishes. Size varies with the cultivar; cherry fruit should be less than 2.5 $\mathrm{cm}$ ( $1 \mathrm{in}$.) in diameter, large fruit should exceed the $2.5 \mathrm{~cm}$ requirement. The more globular forms are preferred. Green shoulders are undesirable. Fruit should be in firm condition and exhibited with the stems left on. In a cross-section, the flesh should be thick, both the outer wall and the sections. The number of sections should be numerous and the amount of pulp and seeds limited. Green-ripe fruit is preferred. Green-ripe fruit has gel in the seed cavity.

Score - Quality 30; Uniformity 25; Condition 20; Color 10; Size 10; Type 5.

a green-ripe fruit will ripen off the vine, gel in the seed cavities indicates fruit is green-ripe

yellow fruit are difficult to grow and are less desirable

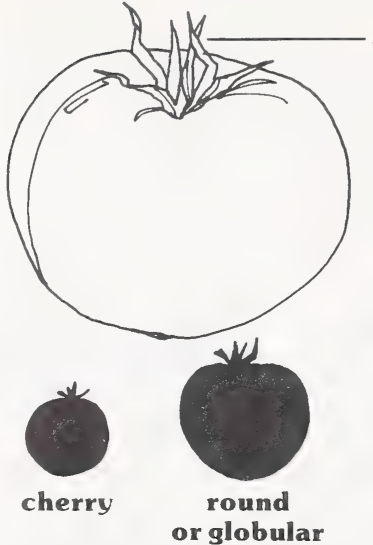

stem must be attached to all fruit

green shoulders are undesirable as they generally ripen last

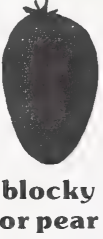

in cross-section amount of pulp and seeds should be

cherry types are the easiest to grow, round or globular types are preferred by the market, blocky types are usually best for processing because of their more fleshy and drier textures

\section{TURNIPS-RUTABAGA}

These include the white fleshed summer turnips and yellow fleshed rutabagas. They should be about $12 \mathrm{~cm}$ ( 4 to $5 \mathrm{in}$.) in diameter, preferably clean, uniform, firm, smooth, and free from all blemishes and woody fibre. Tops should be removed $1 \mathrm{~cm}(0.5 \mathrm{in}$.) above the crown. Rutabagas (Swede turnips) are generally drier and coarser in texture and should be shown in a separate class.

Score-Quality 30; Condition 20; Uniformity 20; Color 10; Size 10; Type 10.

tops should be trimmed to $1 \mathrm{~cm}$ ( 0.5 in.) in length above the crown crown should be smooth and free of greening

rutabaga tends to be yellow fleshed and coarser in texture than turnips which have whiter flesh and are more tender and juicy; each should be in a separate class

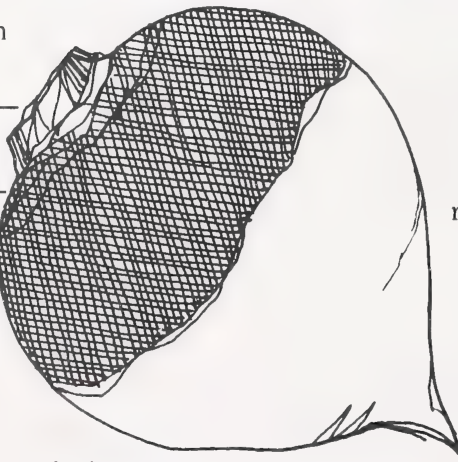

ideal root size measures 10 to 12 $\mathrm{cm}$ (4 to $5 \mathrm{in}$.) in diameter root should be smooth and free of any side roots

trim main root to a reasonable length

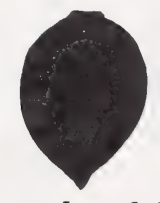
round or globe

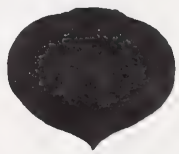

flat thick 


\section{WATERMELON}

There are two types of watermelon - round and oblong. Entries should be uniform, large and smooth. Quality is determined by removing a plug, which should show firm flesh, of deep color, and with a thin rind. Seeds in ripe fruit should be dark brown to black. The stem must be attached to fruit. Watermelon is considered difficult to grow.

Score - Quality 35; Condition 20; Uniformity 20; Size 15; Type 10.

\section{OTHER CLASSES}

Others not listed are judged on quality, condition and uniformity. This class should include the unusual, unique, and those with difficult growth characteristics.

\section{YARDS AND \\ GARDENS Information for show committees}

Garry McCullough ${ }^{6}$ and E.W. Toop, P. Ag. ${ }^{7}$

Only those yards or gardens that have been officially entered should be judged. A judge should not be expected to inspect every home grounds in the town or district and pick the top three or four. He or she should be accompanied by a local official who has the official entries and knows the addresses of all competitors. The judge should not converse with the owners (exhibitors) of the gardens in competition during the course of the judging.

All gardens or yards in the same competition should be judged on the same day. The yards or gardens in the competition must be open for judges to inspect. They cannot be expected to inspect properties from the street or by looking over the back fence.

Because of the differences in space availability, urban home-yard and garden classes should usually be judged separately from rural classes. Rural class descriptions must specify whether the whole farmstead is to be judged or only the home-yard and garden. Acreages and farmsteads can generally be accepted within the bounds of a single class.

In setting up a garden contest it is suggested that the judge be allowed a minimum of 15 minutes to assess each entry. Some entries that are obviously not "in the running" may take less time but topnotch competition will require more consideration than a mere walk through. It is also most helpful if gardens that obviously will not be considered for top place are eliminated in a preliminary examination by the local committee.

\section{Judging standards}

\section{Design}

The judges should assess: the relationship of the house to the garden; and the distribution, proportion and shape of areas within the garden - that is, the general layout and arrangement of lawns, beds, borders, plant material, paths, service and utility areas, and garden structures. The following points should be kept in mind:

${ }^{6}$ Horticulture Department, Olds College, Olds, Alberta

${ }^{7}$ Professor of Horticulture, Department of Plant Science, University of Alberta, Edmonton, Alberta. 
Unity - Does the garden function as a collection of integrated units? Are the individual units coherent?

Interest - Is the garden interesting; that is, are there enough elements (contrast, harmony, graduation, balance, rhythm, emphasis, proportion or scale) introduced in the design to avoid monotony?

Originality - Does the garden show originality of thought and imagination?

Utility - Is the garden functional? Has provision been made for such things as outdoor entertainment and recreation, a supply of cut flowers and vegetables, service area, and comfortable access to, and circulation within, each area?

\section{Maintenance}

Is the garden economically designed from the maintenance point of view?

Trees and shrubs - Are planting distances correct, leaving room for mature size? Have the plants been properly pruned and cared for?

Herbaceous, perennial and annual flowers - Have the materials been correctly planted and spaced for particular effects; correctly staked, thinned and cared for to give strong healthy specimens?

Lawn areas - Have the areas been properly graded before planting? Was the choice of varieties good for the purpose? Is the turf resilient, dense, vigorous, of good color, properly trimmed at edges, cut to proper height, and free from weeds, pests and diseases?

Other areas and structures - What is the condition and upkeep of lane area, garbage cans, fencing, compost heaps, greenhouse and frames, etc.?

\section{Choice of plant material}

Is the material located and spaced to its best advantage, both ornamentally and functionally? Does it suit the soil and climate? Is the form, texture and color attractive and interesting? Have materials been chosen to give an extended period of bloom from early spring to late fall? Is there too much or too little variety of plant material?

\section{Classes}

\section{Home Grounds}

\section{Score}

General arrangement and effect, including features and floral display

Cleanliness

Lawns (health, vigor and trimness)

Trees and shrubs (variety, planting, pruning, and care; freedom from pests and diseases)

Flowers - quality

Total

\section{Vegetable Gardens}

\section{Score}

Quality of the crops 30

Cleanliness (cultivation)

Variety (at least 10 kinds)

Space economy and succession cropping

Arrangement 15

Total 100

The vegetable garden may be judged as a separate entity in some competitions, or in combination with the landscaped portion of the yard (often known as a composite garden). Whichever the case, several general questions can be asked that could help a 
judge ascertain differentials for the score sheet.

There obviously is also a difference between a rural garden and one located in an urban setting. Each judge will therefore have to determine which of the questions given below pertain to any given situation and mark the scoresheets accordingly.

\section{Location}

Is the garden located in the best available location? Is the soil a rich loam?

Is it near a good supply of water or can it easily be reached by sprinkler?

Is it located as near to the house as possible? Garden enthusiasts will use spare time more efficiency if it is easily reached and tools need not be carried back and forth over long distances.

Does surface drainage allow for run off after heavy rains or the melting of snow in the spring? Is it flat enough to prevent soil erosion?

Are the vegetables shaded by trees, shrubs, fences, or walls? Maximum sunlight is needed for best growth. Trees and shrubs take water from the soil to the detriment of the vegetables and also encourage birds which damage young plants.

Is the garden protected from the wind?

\section{Arrangement/management}

Is the garden a small well-cared for one? Or is it a larger somewhat neglected garden?

Are the small fruits, asparagus, rhubarb and other perennial vegetables located in their own special area, often on the edge of the garden approximately one metre from the grass line or fence?

Are the vine crops in the centre of the garden and other crops on each side? Are early vegetables along the edges of the vine crop so that when the vines spread, these vegetables will have been removed?

Are the early crops easily accessible to the homeowner without obstacles to step over, etc.?

Are the tall plants such as corn, tall tomatoes, and staking type peas located on the north side where they will not cast shadows on smaller plants?

\section{AGRICULTURAL EXHIBITS Sheaf grain}

B. J. Godwin 6

Sheaves (wheat, oats; barley, rye, canary seed, flax). One of the most interesting, attractive and lasting crop exhibits is a well-prepared sheaf of grain.

Score Card Points

Maturity and filling of heads $\ldots \ldots \ldots \ldots \ldots \ldots$. 40

Freedom from foreign material ........................ 20

Presentation .................... 40

100

Maturity and filling - The grain must be as mature as possible considering the date of the show. Heads should be large and uniform with plump hard kernels; the straw should be free from mold and mustiness, and dry, bright and ripe in appearance, rather than with green straw and chaff.

${ }^{6}$ Coordinator, Horticultural Programs, Olds College, Olds, Alberta. 
Freedom from foreign material - The sheaf should be free of weeds and other crop plants. It should contain only plants of the same variety, as indicated by the color of straw and chaff, shape of head, presence or absence of awns, etc.

Presentation - Exhibitors of sheaves earn a major part of their reward from showmanship, the art of preparing a pleasing exhibit from carefully selected quality plants. The sheaf should conform to show standards, usually being about $6 \mathrm{~cm}-8 \mathrm{~cm}$ in diameter at the neck. All sheaves should be labelled as to variety.

Suggestions for preparation. To make attractive sheaves choose select plants in the field from well-matured standing grain. Ideal plants will have large, well-filled heads and clean, bright stems. Cut the stems full length and spread out the grain in an airy room away from direct sunlight until cured.

When ready to build the sheaf, strip all leaves from the stems and place a damp cloth over the heads and upper stems to toughen them for handling purposes.

To start the sheaf, select 30 to 40 stems and tie them together to form the central core for the sheaf. Other stems are then placed around the core with each succeeding slightly lower to make a large attractive, rounded bundle of heads. Tie the sheaf firmly in two or three places depending on the length of the straw, and cut off even at the butt. To dress up the sheaf, cover the ties with colored ribbon. When finished, hang up the sheaf with head down until ready for the show. To reduce the possibility of sheaf damage during transport, wrap the head and upper part of the sheaf in cheesecloth.

\section{Baled Hay}

Alfalfa, clover, grass, cereal, mixed hay, native hay (Prairie Wool). While some shows list full bales, others will indicate a "bale slice" of measured thickness, neatly tied and presented.

Score Card Points

Stage of maturity ................. 30

Freedom from foreign material ............ 20

Leafiness, soundness, and curing ........... 40

General appearance ................. 10

100

\section{Explanation:}

The stage of maturity is a major factor influencing the feed value of hay. Alfalfa and sweet-clover should be in the bud to early bloom stage of development. Clovers (except sweet-clover) should show very little bloom (up to one-quarter) and without seed formation in the head. Grasses should be in the emerging head stage (before flowering). Cereals should be in the soft dough stage.

Freedom from foreign material - The sample should be free from weeds, dirt, old stubble and from other crop plants (except mixed hay and Prairie wool).

Leafiness, soundness and curing - The hay should contain a high percentage of leaves; stems should be few and fine, soft and pliable. It should be dry and free from excess moisture. The sample should have a bright green, fresh color and have a fresh aroma. It should be free of mold or mustiness. Hay that is discolored by weathering or overcuring is inferior in feeding value and palatability.

General appearance - The bale or slice should be compact, neat, and securely bound. Complete bales should have the weight indicated on the tag. 
Silage is probably best exhibited in sealed jars. Both grass and legume silage should have high leaf content. Color will be influenced by species and will vary from light green to olive or dark green. The odor will be clean and pleasant, being pungent and pickly rather than putrid, moldy or burned. The texture will be pliable and soft rather than brittle or slimy. A uniform length of cut from $1-4 \mathrm{~cm}$ is desirable.

\section{Forage sheaves}

Grass and legume sheaves are normally intended to show the crop at hay stage. This means a sheaf with emphasis on leaves and early stage of maturity for top quality hay. Forage sheaves are generally picked fresh and exhibited green. The sheaf should be free of weeds and other foreign material and should not be coarse or stemmy.

Grasses and legumes can be picked at the proper hay stage (see baled hay class) and cured by spreading out to dry in an airy room away from direct sunlight. The sheaf is then built from the cured hay.

Forage sheaves are tied once about $10 \mathrm{~cm}$ from the butt. Colored ribbon, covering the tie, may make the sheaf even more attractive.

\section{Field crop seeds}

Includes seeds of cereal grains, flax, canary seed, canola, grasses, field peas, faba beans, lentils and other legumes.

Exhibitors should carefully read and comply with the rules as set out by a particular show committee. The primary consideration is the value of the sample for seed purposes. The show lists will indicate quality required, perhaps in litre volume or by weight.

Score Card Points

Freedom from foreign material ............ 40

Maturity, soundness, plumpness and uniformity ..... 40

General appearance (color, lustre, etc.) . . . . . . 15

Variety ................... 5

100

\section{Explanation:}

Freedom from foreign material - Seed samples should be free of weed seeds, other crop seeds, and trash such as straw chaff and dirt. Samples must be pure as to variety.

Maturity, soundness, plumpness and uniformity - Seeds should be well ripened, with no green or shrunken kernels. Seed should be uniformly plump and well filled, indicating high viability and high weight per unit volume. Samples must be dry and free from mold or mustiness, and free from all diseases, insect injury, and cracked or broken kernels. The hull of oats, barley, grasses and other hulled seeds, should be intact. Frosted and sprouted kernels are objectionable.

General appearance - The sample should be attractive. Seed should be bright in color and uniform in size and appearance.

Exhibit only current year's seed. Always indicate variety. 


\section{Weed collections}

B.J. Godwin 6

Weed collections command interest because they are universally present.

A typical class might call for ten (10) specimens, pressed, dried, mounted and correctly identified.

Points are awarded for quality of workmanship in pressing and mounting; for display, and for correct identification. A current Alberta Weed Designation List is given in Appendix I.

${ }^{6}$ Coordinator, Horticultural Programs, Olds College, Olds, Alberta. 
Amateur - a person who grows plants, flowers, fruits or vegetables for pleasure and enjoyment, and not for monetary gain.

Annual - many kinds of plants, such as gladiolus, dahlia and geranium (Pelargonium), are really perennial flowers but in cold climates are grown as annuals. To avoid confusion, the schedule should specify the kinds of plants considered to be annual.

Areole - a small pit or raised spot, often bearing a tuft of hairs, glochids, or spines as in cacti.

Arrangement - the composition of color, size and shape to produce a pleasing effect. Each unit (flower, fruit, vegetable, etc.) is placed so that collectively they produce a design.

Basket - a container having a fixed handle. Unless otherwise specified, a basket arrangement is to be viewed from all sides and is suitable for home use.

Bloom - one open flower or composite flower head. Usually used when referring to such kinds as aster, dahlia, marigold or petunia. Also used in reference to individual flowers or florets of an inflorescence.

- the fine powdery substance that is the natural covering of certain fruits such as apples, plums and grapes.

Bouquet - see old-fashioned bouquet.

Bowl - a vessel for displaying flowers having a diameter at its mouth equal to or greater than its height.

Buffet arrangement - an arrangement suitable for a buffet table (long and narrow). Schedule must specify whether it is to be viewed from one side only or both sides of the table.

Bunch - refers more to quantity than does the term bouquet. The stems do not need to be tied together or, collectively, of a size to be held in one hand.

Clawing (gladiolus) - refers to a narrowing of petals with a neck-like extension at the point of attachment giving them a claw-like appearance.

Collection - a group of as many different kinds or cultivars as may be possible without sacrificing quality and appearance (unless otherwise specified in the schedule.

Colonial bouquet (nosegay) - several flowers gathered together in a dainty manner. The stems are tied together and subtended by a doily so that they can be held conveniently in one hand.

Color - the normal color of a cultivar or variety at its best. Should be clear, bright and fresh.

Condition - the overall appearance of the exhibit. This is an indication of the exhibitor's skill in growing and preparing an exhibit for show. Involves freshness and the absence of damage or deficiency symptoms.

Cultivar - a horticultural variety. For example, Boskoop Giant is a cultivar of black currant.

Disk flowers or disks (discs) - the individual symmetrical flowers or florets usually found across the central portion of a composite flower head. Collectively they form the button-like or cushion-like centres of single or anemone forms of chrysanthemums and other composites. (The centre of a daisy consists of disk flowers, the outer ones are ray flowers.)

Display - the use of a few or many kinds or cultivars staged for appearance and effect. A type of arrangement. 
Floriferousness - number of flowers present.

Florescence - refers to that portion of an indeterminate inflorescence (for example, gladiolus) in which the florets are open enough to be colorful (half open to fully-open florets usually).

Foliage and stem - judged on strength, straightness and freedom from blemish. The type or accepted standard should be kept in mind.

Form - refers to shape and structure. A good flower has no deformities, not even small ones.

Fragrance - difficult to assess objectively. Consideration should be given to fragrance in the event of close competition in flower classes.

Glochid - a minute barbed spine or bristle, often in tufts as in many cacti.

Hard nose - a strawberry with a hard, damaged or undeveloped end.

Harmony - term applied to arrangements indicating a pleasing interrelationship among the various components making up the arrangement. It includes harmony of color, texture, shape and design.

Incurved - curved or bent inward or upward (opposite of recurved).

Inflorescence - the flowering part of a plant consisting of florets or blooms arranged on an axis (rachis). It may be determinate (definite number of florets with top or innermost floret opening first) or indeterminate (indefinite number of florets with lowest or outermost floret opening first).

Involute - rolled inward from the edge (opposite of revolute).

Kind - usually refers to plant genera, but there are exceptions. For example, currants and gooseberries are two kinds of fruit yet black, red and white currants may be treated as kinds for exhibition purposes. (Where there is likely to be doubt, the schedule should specify.)

Laciniated - cut into narrow irregular lobes, slashed, jagged. Having a fringed border.

Novice - a competitor who has not won prizes at a previous show.

Old-fashioned bouquet - collection of favorite flowers in a container or vase, but neither arranged nor with the stems tied together.

Patina - gloss on leaves or fruit.

Petalage - refers to number, shape, size and arrangement of petals of a flower.

Professional - a person who grows plants, flowers, fruits or vegetables for monetary gain for himself or an employer; or anyone employed in the maintenance of a garden or park.

Ray flowers, or rays - the individual showy strap-like flowers, or florets, of a composite flower head such as dahlia, chrysanthemum or aster. Often mistaken for petals.

Recurved - curved or bent outward or downward (opposite of incurved).

Revolute - both edges of a petal or a leaf are rolled backward lengthwise onto the lower surface toward the centre or midrib.

Size - as large as the standard, or type, but not coarse. The largest bloom or inflorescence is not necessarily the best.

Spike - an inflorescence with a central axis (rachis) to which flowers are directly attached (for example, gladiolus or salvia). 
Spray - a much-branched inflorescence, such as phlox, nemesia and salpiglossis; sometimes referred to as a bunch.

Stalk - the plant part (pedicel) that attaches each bloom to the central axis of a spike inflorescence or to the branches of a spray inflorescence. In many prize lists the term stalk is incorrectly used to mean an entire inflorescence of either the spike or spray type.

Standard - the size and quality accepted in the market place.

Stem - refers to the central axis of a spike or the individual branches of a spray. This term when used in prize lists should mean one spike inforescence or one detached branch of a spray inforescence, or one composite flower head or single blossom on a long individual stalk or pedicel.

Substance - refers to the ability of petals to return to their normal position if moved out of place. Involves thickness of petals, keeping quality and resistance to damage from handling.

Succulent - a plant with very fleshy leaves or stems or both; juicy, soft and thickened in texture.

Texture - the characteristic disposition of the constituent parts of an arrangement. Texture may be delicate, fine, coarse, smooth, etc. (see harmony).

Turgid - fully hydrated - the opposite of wilted, or flaccid.

Type - the accepted standard.

Vase - a vessel for displaying flowers having a height greater than the diameter of its mouth.

Variety - a botanic variety of a species. Sometimes used to mean a horticultural variety or cultivar. 
Thanks are extended to the many persons who offered constructive criticism in the preparation of this manual, both in its original printing and in this revised edition.

\section{APPENDIX}

\section{Appendix I \\ GOVERNMENT OF THE PROVINCE OF ALBERTA \\ ALBERTA REGULATION 138/80}

(Filed on April 23, 1980)

THE WEED CONTROL ACT, 1979

(O.C. 396/80)

Approved and Ordered

F. LYNCH-STAUNTON Lieutenant Governor

Edmonton, April 22, 1980

Upon the recommendation of the Honourable the Minister of Agriculture, the Lieutenant Governor in Council, pursuant to section 40 of The Weed Control Act 1979 makes the regulation in the attached Appendix, being the Weed Designation Regulation.

L.D. HYNDMAN (Acting Chairman)

\section{THE WEED CONTROL ACT 1979}

Weed Designation Regulation

1. The following plants are designated as restricted weeds in Alberta.
(a) Red bartsia - Odontites serotina L.
(b) Diffuse knapweed - Centaurea diffusa L.
(c) Spotted knapweed - Centaurea maculosa L.
(d) Nodding thistle - Carduus nutans L.
(e) Eurasian Water Milfoil - Myriophyllum spicatum L.

2. The following plants are designated as noxious weeds in Alberta.
(a) Russian knapweed - Centaurea repens L.
(b) Field bindweed - Convolvulus arvensis L.
(c) White Cockle - Lychnis alba.
(d) Bladder campion - Silene cucubalus.
(e) Cleavers - Galium aparine L.
(f) Hoary cress - Cardaria spp.
(g) Knawel-Scleranthus annuus L.
(h) Perennial sow thistle - Sonchus arvensis L.
(i) Cypress spurge - Euphorbia cyparissias L.
(j) Leafy spurge - Euphorbia esual L.
(k) Stork's bill - Erodium cicutarium L.
(l) Canada thistle - Cirsium arvense L.
(m) Toadflax - Linaria vulgaris.
(n) Persian darnel - Lolium persicum.
(o) Scentless Chamomile - Matricaria maritima L.
(p) Common tansy - Tanacetum vulgare L.

3. The following plants are designated as nuisance weeds in Alberta.
(a) Dalmation toadflax - Linaria dalmatica L.

(a1) Wild radish - Raphanus raphanistrum L. 
(b) Creeping bellflower - Campanula ranunculoides L.

(b1) Hedge bindweed - Convolvulus sepium L.

(c) Bluebur - Lappula echinata.

(c1) Blueweed - Echium vulgare L.

(d) Downy brome - Bromus tectorum

(d1) Tartary buckwheat - Fagopyrum tataricum.

(e) Wild buckwheat - Polygonum convolvulus.

(e1) Biennial campion - Silene eserei.

(f) Night-flowering catchfly - Silene noctiflora L.

(f1) Common chickweed - Stellaria media L.

(g) Field chickweed - Cerastium arvense L.

(g1) Mouse-eared chickweed - Cerastium vulgatum L.

(h) Rough cinquefoil - Potentilla norvegica L.

(h1) Cow cockle - Saponaria vaccaria L.

(i) Flixweed - Descurainia sophia L.

(i1) Green foxtail - Setaria viridis L.

(j) Quack grass - Agropyron repens L.

(j1) Narrow-leaved hawk's-beard - Crepis tectorum L.

(k) Hemp nettle - Galeopsis tetrahit $L$.

(k1) Henbit - Lamium amplexicaule L.

(l) Lady's thumb - Polygonum persicaria L.

(m) Round-leaved mallow - Malva rotundifolia L.

(n) Ball mustard - Neslia paniculata.

(o) Dog mustard - Erucastrum gallicum.

(p) Green tansy mustard - Descurainia pinnata.

(q) Wild mustard - Sinapis arvensis L.

(r) Wormseed mustard - Erysimum cheiranthoides.

(s) Wild oats - Avena fatua L.

(t) Redroot pigweed - Amaranthus retroflexus L.

(u) Shepherd's-purse - Capsella bursa-pastoris L.

(v) Annual sow thistle - Sonchus oleraceus L.

(w) Corn spurry - Spergula arvensis L.

(x) Stinkweed - Thlaspi arvense L.

(y) Russian thistle - Salsola pestifer.

(z) Dandelion - Taraxacum officinale.

4. Alta. Regs. $147 / 73$ as amended and $279 / 58$ are repealed. 
